Department of Economics- FEA/USP

\title{
Conditional Betas and Investor Uncertainty
}

\author{
Fernando D. Chague
}

WORKING PAPER SERIES № 2013-04 


\title{
DEPARTMENT OF ECONOMICS, FEA-USP \\ WORKING PAPER № 2013-04
}

\section{Conditional Betas and Investor Uncertainty}

Fernando D. Chague (fchague@usp.br)

\begin{abstract}
:
We derive theoretical expressions for market betas from a rational expectation equilibrium model where the representative investor does not observe if the economy is in a recession or an expansion. Market betas in this economy are time-varying and related to investor uncertainty about the state of the economy. The dynamics of betas will also vary across assets according to the assets' cash-flow structure. In a calibration exercise, we show that value and growth firms have cash-flow structures that imply an opposing beta dynamics that goes in the direction of solving the value premium puzzle. During high uncertainty periods, value betas are higher while growth betas are lower. We estimate conditional betas empirically using proxies for investor uncertainty and show support of the model's prediction about the dynamics of growth and value betas.
\end{abstract}

Keywords: Conditional CAPM, Conditional Betas, Uncertainty

JEL Codes: G12, E32, D80 


\title{
Conditional Betas and Investor Uncertainty
}

\author{
Fernando Chague*
}

April 15, 2013

\begin{abstract}
We derive theoretical expressions for market betas from a rational expectation equilibrium model where the representative investor does not observe if the economy is in a recession or an expansion. Market betas in this economy are time-varying and related to investor uncertainty about the state of the economy. The dynamics of betas will also vary across assets according to the assets' cash-flow structure. In a calibration exercise, we show that value and growth firms have cash-flow structures that imply an opposing beta dynamics that goes in the direction of solving the value premium puzzle. During high uncertainty periods, value betas are higher while growth betas are lower. We estimate conditional betas empirically using proxies for investor uncertainty and show support of the model's prediction about the dynamics of growth and value betas.
\end{abstract}

Keywords: Conditional CAPM, Conditional Betas, Uncertainty

JEL Codes: G12, E32, D80

\section{Introduction}

The conditional Capital Asset Pricing Model (CAPM) does not impose any structure on how betas should vary. This has largely been tackled from an empirical perspective. Early parametrical approaches include the multivariate GARCH framework (Bollerslev et al., 1988) and the instrumental variables betas (Harvey (1989), Harvey and Kirby (1996)). Recent parametric models suggest treating conditional betas as latent variables: Adrian and Franzoni (2009) suggest using the Kalman filter while Ang and Chen (2007) apply Markov-chain Monte-Carlo and Gibbs sampling to obtain time varying betas. Non-parametric approaches have been suggested by Andersen et al. (2006), who use high-frequency data to estimate betas and Ang et al. (2006), who point out how asymmetries in

${ }^{*}$ Department of Economics, University of São Paulo, email: fchague@usp.br. I'm grateful for comments from Eric Ghysels, Mike Aguilar, Marco Bonomo, Tim Bollerslev, Saraswata Chaudhuri, Rodrigo De-Losso, David Fragoso Gonzalez, Walter Novaes, Bruno Giovannetti, Ruy Ribeiro, and Eric Renault, and seminar participants at University of North Carolina, Triangle Econometrics Workshop, EAESP-FGV and Lubrafin Meeting. All errors are my own. 
betas may be important. Despite the number of available models, many papers still use the rolling betas of Fama and MacBeth (1973) to avoid taking a stand on a more restrictive econometric model (Lewellen and Nagel, 2006).

In this paper, we derive the dynamics of market betas from an economic theoretical perspective. More specifically, we consider a multiple asset version of the rational expectations equilibrium model of Veronesi (1999), studied by Ribeiro and Veronesi (2002). In this model, the investor is uncertain about the true distribution of each asset's cash-flow stream. In particular, the investor does not observe the drift of the continuous process that characterizes cash-flows, which can take on two values according to a Markov-chain process. The two values the drift can take are associated with good and bad times of the economy. As a result of this uncertainty, investor decisions and pricing formulas are affected by a learning process. We show that in this economy, as in Merton's (1973) ICAPM, expected returns can be decomposed by the asset's exposures to the two common sources of risk, the market and a hedging risks. The structure imposed on asset's cash-flows also allows for formulas of conditional betas and prices of risk.

In a calibration exercise, we show that the model can capture the cross-section variation of stock returns with reasonable parameters. We calibrate an economy with cash-flow data from book-tomarket portfolios, and the model's unconditional moments match the sample moments of returns. The calibration exercise reveals that the cash-flow of the value portfolio is much more susceptible to changes in the economic conditions than the cash-flow of the growth portfolio. Furthermore, the calibration also shows that the exposure to the market risk is much more important than the exposure to the hedging risk, and that a conditional CAPM (with the specified dynamics) can explain expected returns.

The main findings about market betas are the following. First, investor uncertainty about the state of the economy plays an important role in the dynamics of market betas. Assets that are more susceptible to changes in the economic conditions tend to have higher betas during periods of high uncertainty, while assets that are less susceptible tend to have lower betas. For instance, we observe that value betas tend to be higher during periods of high uncertainty, while growth betas tend to be higher during periods of low uncertainty. Furthermore, since uncertainty is usually higher during recessions, this asymmetric behavior of value and growth betas points to a counter-cyclical value premium. This counter-cyclicality of the value premium predicted by the model is also confirmed 
empirically by Petkova and Zhang (2005) .

Second, good and bad news about the economy have different impacts on market betas, depending on whether the markets are in good or bad times. Since bad news during good times tends to increase uncertainty, as opposed to good news during good times which tends to decrease uncertainty, market betas, that respond to uncertainty, may either increase or decrease, depending on the sign of news. Because the economy is typically in good times, i.e. expansions last longer than recessions, the average bad news will increase uncertainty and thus increase the value beta, as revealed by our calibration exercise.

In order to confirm if these two theoretical findings about market betas are indeed observed in the data, we perform two empirical exercises with U.S. stock returns data. First, we propose a model for market betas that relates it to investor uncertainty. The estimated parameters confirms the shapes predicted by the model, namely that value betas tend to be higher during periods of high uncertainty and that growth betas tend to be lower during periods of high uncertainty. Second, we estimate betas conditional on the sign of returns. The idea is to proxy news by stock returns, and verify whether value betas conditional on negative news tend to be higher than when conditional on positive news. Again, the empirical results points in the direction predicted by the model.

Our paper is related to Santos and Veronesi (2004), who derive implications to market betas within a general equilibrium model. The model assumes that the investor has habit persistent preferences and that the dividends in the economy are random shares of the total endowment of the economy. They find that betas can be decomposed into a cash-flow risk and a discount risk components and that the dynamic of conditional betas is determined by the component that is most important.

Our finding that value and growth stocks have opposing cash-flow dynamics and, as a result, different pricing dynamics, relates to Koijen et al. (2012). The paper shows that a three factor model can explain the cross-section of returns of value and growth portfolios. The key factor behind the result is based on the nominal bond risk premium of Cochrane and Piazzesi (2005), which measures the cyclical variation in the market's perception of the economy output growth, and is thus similar to our state variable based on the investor uncertainty about the state of the economy. However, they consider a static factor model rather than a conditional factor model, and the theoretical framework is also different than ours. 
The paper proceeds as follows: in section (2), we solve the model and discuss the resulting asset pricing formulas. In section (3), we calibrate the model with U.S. data. Then, in section (4) we propose an econometric model that estimates empirically the beta dynamics. We conclude the paper with a brief summary of the results and some final remarks.

\section{The Model}

The model is a multiple asset version of the rational expectations equilibrium model of Veronesi (1999) derived by Ribeiro and Veronesi (2002). The authors show how uncertainty about the state of the world economy can result in the observed excess covariation in international stock markets during downturns. In this paper, we investigate the dynamics of the different components of the risk premia and, in particular, how good and bad news are incorporated into market betas.

\subsection{The Economy}

In this economy, there is one representative investor that maximizes expected utility subject to a budget constraint. There are $n+1$ financial assets, a risk-free asset that is inelastically supplied with a known rate of return $r d t$, and $n$ risky assets that pay continuous stream of cash-flows, given by:

$$
d D_{i t}=\theta_{i t} d t+\sigma_{i} d \xi_{t} \quad i=1, \ldots, n
$$

where $d \xi_{t}$ is a $(n \times 1)$ vector of Brownian motions and $\sigma_{i}$ a $(1 \times n)$ vector of diffusion coefficients. These $n$ expressions can be written in matrix notation as $d D_{t}=\theta_{t} d t+\Phi d \xi_{t}$, where $\theta_{t}$ is the $(n \times 1)$ vector of drift terms $\theta_{i t}$, and $\Phi$ is the $(n \times n)$ matrix that stacks the diffusion terms $\sigma_{i}$. Denote by $\Sigma=\Phi \Phi^{\prime}$ the cash-flow covariance matrix. The market portfolio cash-flow is defined as the sum of all cash-flows times the available shares of each asset, $D_{m t} \equiv \sum_{i=1}^{n} \omega_{i} D_{i t}$, where $\omega=\left[\omega_{1}, \ldots, \omega_{n}\right]^{\prime}$ are the available shares.

The investor does not observe the random vector $\left\{\theta_{t}\right\}$ but knows it can take two values: $\theta_{G}=$ $\left[\theta_{1 G}, \ldots, \theta_{n G}\right]^{\prime}$ in the good state and $\theta_{B}=\left[\theta_{1 B}, \ldots, \theta_{n B}\right]^{\prime}$ in the bad state. This random vector switches between the two states with conditional probabilities that follow a two-state Markov-chain process with parameters $\mu$, the probability of going to a good state from a bad state, and $\lambda$, the probability of shifting from the good state to the bad state. The same Markov-switching process 
governs the shifts of all drifts and can be associated with business cycles shifts. We say asset $i$ is cyclical if $\Delta \theta_{i} \equiv \theta_{G}-\theta_{B}>0$ and countercyclical otherwise.

The investor optimally infers the true drifts of cash-flows from past observations. That is, he conditions his beliefs about the true drifts on the information set $\mathcal{F}_{t}=\sigma\left(D_{\tau}, \tau<t\right)$. As was shown by Veronesi (1999), the optimal prediction is conveniently described by a stochastic process. The following lemma is an extension of the univariate case for multiple assets.

Lemma 1. The investor's belief that the economy is in the good state, $\pi_{t} \equiv \operatorname{Prob}\left(\theta_{t}=\theta_{G} \mid \mathcal{F}_{t}\right)$, evolves according to the stochastic process:

$$
d \pi_{t}=(\lambda+\mu)\left(\pi_{s}-\pi_{t}\right) d t+\pi_{t}\left(1-\pi_{t}\right) \Delta \theta^{\prime} \Phi^{\prime-1} d v_{t}
$$

where $\pi_{s}=\frac{\mu}{\lambda+\mu}$ is the unconditional probability of $\pi_{t}, \Delta \theta^{\prime}=\left[\theta_{1 G}-\theta_{1 B}, \ldots, \theta_{n G}-\theta_{n B}\right]$, and $d v_{t} \equiv$ $\Phi^{-1}\left(d D_{t}-E\left[d D_{t} \mid \mathcal{F}_{t}\right]\right)$ is a $(n \times 1)$ vector of standard Brownian motions with respect to the filtration $\mathcal{F}_{t}$, with $E\left[d D_{i t} \mid \mathcal{F}_{t}\right]=\theta_{i G} \pi_{t}+\theta_{i B}\left(1-\pi_{t}\right)$ for $i=1, \ldots, n$.

Proof. It follows from theorem 9.3 in Lipster and Shiryaev (2001).

Note that $\pi_{t}$ mean reverts towards its unconditional mean, $\pi_{s}$, at a rate of $\lambda+\mu$. Shocks to $d v_{t}$ are weighted by a signal to noise ratio, $\Delta \theta^{\prime} \Phi^{\prime-1}$, and by the uncertainty level about the state of the economy, $h\left(\pi_{t}\right) \equiv \pi_{t}\left(1-\pi_{t}\right)$. The closer $\pi_{t}$ is to 0.50 , the more uncertain the investor is about the true state, and the larger the revisions to the conditional probability are. For ease of notation, let $\alpha_{\pi} \equiv(\lambda+\mu)\left(\pi_{s}-\pi_{t}\right)$ and $\sigma_{\pi}^{2} \equiv \pi_{t}^{2}\left(1-\pi_{t}\right)^{2} \Delta \theta^{\prime} \Sigma^{-1} \Delta \theta$. We will also denote the $(1 \times n)$ vector by $\sigma_{\pi} \equiv \pi_{t}\left(1-\pi_{t}\right) \Delta \theta^{\prime} \Phi^{\prime-1}$. Also, note that whenever expansions last longer than recessions, $\lambda<\mu$, the unconditional mean $\pi_{s}$ will be greater than 0.50 , that is, the market will be good more often than $\operatorname{not}^{1}$.

In this economy investor preferences are represented by a constant absolute risk aversion utility function:

$$
U(c, t)=-\exp [-\rho t-\gamma c]
$$

\footnotetext{
${ }^{1}$ In fact, NBER cycles imply an unconditional mean of around $\pi_{s}=0.80$
} 
where $\gamma$ is the coefficient of absolute risk aversion and $\rho$ the time preference parameter.

Under the incomplete information set, $\mathcal{F}_{t}$, cash-flows can be written as $d D_{t}=\alpha_{D t} d t+\Phi d \mathbf{v}_{t}$, where $\alpha_{D t}=\left[\alpha_{1 D, t}, \ldots, \alpha_{n D, t}\right]^{\prime}$ and $\alpha_{i D, t} \equiv \theta_{i G} \pi_{t}+\theta_{i B}\left(1-\pi_{t}\right)$. The investor's optimization problem is solved by expressing $d D_{t}$ in terms of the Brownian motion $d \mathbf{v}_{t}$ and including $\pi_{t}$ as a state variable. Pricing formulas are obtained by imposing a market clearing condition on the available shares of the risky assets. We refer the reader to the Appendix for a more detailed derivation of the model.

Expected return is defined as $R_{i t}^{e} \equiv \frac{d P_{i t}}{P_{i t}}+\frac{D_{i t}}{P_{i t}} d t-r d t$ and, as in Merton (1973), can be expressed in terms of compensation to exposures to risk, as we show in the following proposition.

Proposition 2. Expected returns have the following factor representation:

$$
E_{t}\left[R_{i t}^{e}\right]=\lambda_{m t} \beta_{i m, t}+\lambda_{\pi t} \beta_{i \pi, t}
$$

where the prices of risk are given by

$$
\begin{aligned}
& \lambda_{m t}=r \gamma P_{m t} \sigma_{m R, t}^{2} \\
& \lambda_{\pi t}=f^{\prime}\left(\pi_{t}\right)-r \gamma S_{m}^{\prime}\left(\pi_{t}\right)
\end{aligned}
$$

and conditional betas, defined as $\beta_{i m, t} \equiv \frac{\sigma_{i m, R}}{\sigma_{m, R}^{2}}$ and $\beta_{i \pi, t} \equiv \sigma_{i \pi, R}$, are given by

$$
\begin{aligned}
\beta_{i m, t} & =\frac{P_{m t}}{P_{i t}} \times \frac{\left(A_{i m}+M_{i m}\left(\pi_{t}\right)\right) h\left(\pi_{t}\right)^{2}+\left(B_{i m}+N_{i m}\left(\pi_{t}\right)\right) h\left(\pi_{t}\right)+C_{i m}}{\left(A_{m m}+M_{m m}\left(\pi_{t}\right)\right) h\left(\pi_{t}\right)^{2}+\left(B_{m m}+N_{m m}\left(\pi_{t}\right)\right) h\left(\pi_{t}\right)+C_{m m}} \\
\beta_{i \pi, t} & =\frac{1}{P_{i t}}\left[\left(p_{i \pi}+S_{i}^{\prime}\left(\pi_{t}\right)\right) h\left(\pi_{t}\right)^{2}+\frac{h\left(\pi_{t}\right) \Delta \theta_{i}}{r}\right]
\end{aligned}
$$

where $A, B, C, M$ and $N$ are given in proposition (4) in the appendix. The functions $f$ and $S$ are solutions to differential equations given in the Appendix.

Proof. The expression for expected returns (13) follows by rewriting the optimal demand for shares, equation (10) in Appendix, in terms of expected returns and substituting for the market clearing condition, $X_{t}^{*}=\omega$. After scaling by the market variance, $\sigma_{m, R}^{2}$, we obtain market betas and prices 
of market risk. The expressions of betas in terms of the primitive parameters of the model follow after substituting for the covariances and variances given in (4).

The first component of expression (3) is the usual conditional CAPM term, with variable beta and price of risk. The conditional market beta is defined as the ratio of the conditional covariance of asset and market excess returns normalized by the conditional variance of the market excess returns, $\beta_{i m, t}=\sigma_{i m, R} / \sigma_{m, R}^{2}$. This measure of risk captures the responsiveness of asset returns to changes in market returns. An asset with a high market beta will be riskier as it amplifies the volatility, or risk, of the investor's portfolio. Indeed, the price of market risk is positive as all elements in $\lambda_{m t}$ are greater than zero, and assets with high betas reward the investor with higher returns.

Since expressions for asset returns are available, given by proposition (4), we can substitute covariances and variances of returns by their functional forms and link market betas to the parameters of the model and the state variables. As equation (4) shows, the market beta is a non-linear function of $\pi_{t}$ and depends upon the discounting function $S$ that can only be obtained numerically.

The second term of the expected returns expression (3) results from the time-varying nature of the investment opportunity set (Merton, 1973). Note that the drift and diffusion terms of stock returns in equation (13) are functions of the random variable $\pi_{t}$ and are thus stochastic. Assets that can help the investor hedge against future changes in profitability should be more expensive, i.e. have lower expected returns. The exposure of an asset to this source of risk is measured by its factor loading, defined as $\beta_{i \pi, t} \equiv \sigma_{i \pi, R}$, and is also equal to (5). We observe that assets that are very sensitive to changes in $\pi_{t}$, and have a large state shift risk, i.e. a large $\Delta \theta_{i}$, also have large betas. The price of a unit of such risk is given by $\lambda_{\pi t}$ and it can be positive or negative, depending on the function $f$ and the market discount $S_{m}$ function. For the parameters selected in the next section, the price of risk is negative at lower values of $\pi_{t}$ and positive for higher values.

\section{Calibration of the Model}

In order to draw further conclusions from the above formulas, we calibrate an economy with five 
assets, each following one of the five book-to-market sorted portfolios, with parameters obtained from the U.S. economy. The cash-flow parameters implied by such portfolios varies substantially across quintiles and provide an appropriate framework for this investigation. This variation across quintiles is in line with the perception that low book-to-market firms (growth firms) derive most of their profitability from future cash-flows as opposed to value firms, that derive most of their profitability from current cash-flows and assets and that, as a result, are more susceptible to the current economic conditions. Indeed, general equilibrium models that explain the value premium anomaly $^{2}$ often explore the differences in the investment and cash-flow characteristics of those firms (Berk et al. (1999), Gomes et al. (2003) and Zhang (2005)).

For this calibration, we set the risk aversion parameter equal to one, $\gamma=1$, as in Veronesi (2004). The other free parameters of the model are calibrated from the U.S. economy. The risk-free instantaneous rate is set at $r=0.045$, a relatively high value but close to the average one month treasury bill rate on the same period $(4.9 \%)$.

The free parameters of the cash-flow processes are: the drift vectors $\theta_{G}=\left[\theta_{1 G}, \ldots, \theta_{5 G}\right]^{\prime}$ and $\theta_{B}=\left[\theta_{1 B}, \ldots, \theta_{5 B}\right]^{\prime}$, the diffusion matrix $\Phi$, and the scalars of the Markov-switching transition matrix $\mu$ and $\lambda$, that characterize the random switches of the drifts. For the transition matrix, we select the parameters implied by the NBER cycles data ${ }^{3}$ from 1956 to 2010. As shown in Panel A of Table 1, the NBER cycles data indicate $83.3 \%$ of the months are expansionary, with an average duration of a recession of 11 months and of an expansion of 62 months. These numbers imply ${ }^{4}$ the following monthly transition matrix parameters: $\lambda=0.016$, the probability of going from the good state to the bad state, and $\mu=0.080$, the probability of switching to the good state from the bad state.

The drifts of the cash-flows $\theta_{G}$ and $\theta_{B}$ are calibrated ${ }^{5}$ using the moments implied by the $\log$ dividend growth of the five book-to-market portfolios data ${ }^{6}$, from 1956 to 2010. The log-dividend

\footnotetext{
${ }^{2}$ The discrepancy of high and low book-to-market portfolios expected returns relative to the static CAPM predictions.

${ }^{3}$ http://www.nber.org/cycles.html

${ }^{4}$ From the NBER average length of an expansion we obtain $\lambda \equiv \operatorname{prob}\left(S_{t+1}=\operatorname{Bad} \mid S_{t+1}=\right.$ Good $)$ by setting the average sample duration of an expansions equal to $1 / \lambda . \mu \equiv \operatorname{prob}\left(S_{t+1}=\operatorname{Good} \mid S_{t+1}=\operatorname{Bad}\right)$ is then obtained by setting $\mu /(\mu+\lambda)$ equal to the proportion of expansionary months in the sample.

${ }^{5}$ Because of the assumption that cash-flows follow arithmetic Brownian motions and that the data actually show exponential growth of dividends, the parameters used for calibration, based on log-differences, are only valid as approximations, and particularly around cash-flow levels close to one.

${ }^{6}$ The data was obtained from the website of Kenneth French.
} 
growth series are constructed from the difference in the monthly returns with and without dividend payouts as in Bansal et al. (2005). In order to avoid seasonal variations typical to dividend payouts, monthly log-dividend growth are aggregated at the annual frequency. Panel B of Table 1 shows the sample means and the standard deviations of log-dividend growth for the five bookto-market portfolios on the full sample as well as the means and standard deviations conditional on recessionary and expansionary years ${ }^{7}$. The log-dividend growth average of the value portfolio varies the most across the two sub-samples, from -0.130 during recessionary years to 0.109 during expansionary years. The difference in the conditional averages is 0.239 . On the other hand, the log-dividend growth averages of the growth portfolios change the least, 0.058 and 0.046 in recessions and expansions respectively. The difference in the conditional averages is -0.011 .

The log-dividend series are very volatile and the distinctive pattern between value and growth portfolios may not be supported on statistical grounds. However, this pattern is roughly monotonic across quintiles, particularly the average log-dividend growth during recessions, indicating this to be an economically meaningful pattern related to the book-to-market ratio. Furthermore, it has been argued that value firms are particularly susceptible to economic downturns, which is in line with our empirical findings. For instance, Fama and French (1993) conjectured that value firms are riskier than growth firms because a higher book-to-market ratio associates most often with distressed firms. Also, Zhang (2005) characterizes value firms as those with costly-to-adjust investments (e.g. asset's in place type of investment) and thus those with cash-flow more susceptible to adverse shocks, i.e. recessions, whereas growth firms as those with more flexible investments scales (e.g. growth options type of investment) and thus those with cash-flow less sensitive to fluctuations in economic conditions. The empirical findings above combined with the economic theory indicates that a reasonable calibration for the changes in the cash-flow drift, $\Delta \theta_{i}=\theta_{i G}-\theta_{i B}$, to be larger for the value portfolio and smaller for the growth portfolio.

The numbers chosen for the drifts $\theta_{G}$ and $\theta_{B}$, and diffusion matrix $\Phi$ follow the patterns observed by the data but also are such that the model's implied unconditional excess return are similar to real data sample averages. Because the model cannot exclude a priori negative prices, this calibration strategy ensures that prices, and therefore returns, are within a reasonable range.

\footnotetext{
${ }^{7} \mathrm{~A}$ year is considered a recessionary year if five or more months are recessionary months according to the NBER data
} 
Table 2 shows the parameters chosen for assets 1 to 5 , that respectively mimic the lowest to highest book-to-market quintile portfolios. Asset 1 (A1), that resembles the growth portfolio, has the lowest state-shift risk among the assets, $\Delta \theta_{1}=-0.01$, the lowest unconditional drift, $\bar{\theta}_{1}=0.04$, and the largest volatility $\sigma_{1}=0.16$. On the other side is asset $5(\mathrm{~A} 5)$, that resembles the value portfolio. It has the highest state-shift risk, $\Delta \theta_{5}=0.23$, but also the highest unconditional drift $\bar{\theta}_{5}=0.062$ and the lowest volatility, $\sigma_{5}=0.09$. Note that this diffusion term is smaller than the one implied by the data. This was needed to match sample and theoretical returns, a result of our calibration strategy discussed above ${ }^{8}$. The correlation parameters, $\rho_{i j}$, were set equal to 0.25 , $0.15,0.10$ and 0.05 for $|i-j|$ equal to $1,2,3$ and 4 , respectively, and sets a higher correlation to portfolios with similar book-to-market values. Table 2 also shows the expected excess returns and deviations at $\pi_{t}=\pi_{s}$ implied by the model, i.e. the unconditional moments, as well as the sample counterparts of the five book-to-market portfolios ${ }^{9}$. A comparison of the values on Panel B and Panel $\mathrm{C}$ shows that the model reproduces the cross-section dispersion on expected returns of the book-to-market portfolios for reasonable parameters.

Figure 1 shows the model's main expressions for all possible values of $\pi_{t}$ and fixed cash-flows at $D_{t}=1$. On the top-left plot, we see that A1 has the highest price on almost all the domain of $\pi_{t}$. This asset is the least profitable, as it has the lowest unconditional drift among all cash-flows, but also the least susceptible to changes in the economic conditions and so less risky. At the other extreme is asset A5, which is the most profitable one, but also the most risky and discounted one, with the lowest price on almost all the domain of $\pi_{t}$. In the top-right plot we see that expected returns for asset $\mathrm{A} 5$ is the most sensitive to $\pi_{t}$, changing from $3 \%$, when $\pi_{t}$ is close to one, to almost $15 \%$, when uncertainty is higher. All the other cyclical assets also have increasing expected returns on uncertainty, but the change is less substantial. The expected return on the countercyclical asset A1 slightly declines on uncertainty. The second row in Figure 1 shows covariances of the assets with the market as well as the variances of asset returns. The shapes are similar to the ones implied by the risk-neutral case, but peaking slightly to the right of the maximum uncertainty point, around $\pi_{t}=0.6$.

\footnotetext{
${ }^{8}$ If we imposed a higher variance for A5 cash-flow and kept the state-risk spread, this would have resulted in a very risky asset with an incompatible high expected returns. We preferred to keep the state-risk spread but reduce the diffusion risk.

${ }^{9}$ Cash-flow levels are set at 1 . At this point, the drift parameters better approximate the log-dividend changes that were used to calibrate them.
} 
The last four plots in Figure 1 show all the elements in the factor decomposition of excess returns (2), the market betas, $\beta_{i m, t}$, hedging betas, $\beta_{i \pi, t}$, and their corresponding prices, $\lambda_{m, t}$ and $\lambda_{\pi, t}$, as functions of all possible values of $\pi_{t}$ and given cash-flows. First, we observe that the premium for exposure to market risk is more important than the premium for exposure to hedging risk. The most sensitive asset to the hedging factor, A5, has the highest absolute hedging premium at $\pi_{t}=0.75$ when $\lambda_{\pi t} \beta_{5 \pi, t}=-1 \%$. At the same point, the risk premium for market risk is much larger, around $\lambda_{m t} \beta_{5 m, t}=15 \%$. This confirms Merton's (1980) observation that the market portfolio is likely the most important factor determining expected returns and justifies the assumption made by Jagannathan and Wang (1996) of hedging motives not being sufficiently important.

Second, market beta of assets with a high and positive $\Delta \theta_{i}$, such as A5, increases as uncertainty about the state of the economy increases. Since the investor is risk-averse, the market beta of asset A5 peaks slightly above ${ }^{10}$ the point of maximum uncertainty, taking its maximum value of $\beta_{5 m, t}=1.80$ at around $\pi_{t}=0.60$. On the other hand, the beta of asset A1, declines as $\pi_{t}$ moves away from 0 and 1 , reaching a minimum of $\beta_{1 m, t}=0.40$ also around $\pi_{t}=0.60$. We note also that there is enough variation in betas to make A1 riskier than A5. In periods of low uncertainty, e.g. when $\pi_{t}>0.95$, the beta of $\mathrm{A} 1$ is higher than that of A5.

Third, the price of market risk, or the market premium, is positive and also increasing on uncertainty. It reaches a maximum of about $\lambda_{m t}=8 \%$ at $\pi_{t}=0.60$ and a minimum of $\lambda_{m t}=3 \%$ at $\pi_{t}=1$. At $\pi_{s}=0.83$, the unconditional or long run mean of the random variable $\pi_{t}$, the price of market risk is $6.5 \%$ and close to its historical sample mean ${ }^{11}$.

Finally, time-variation of market betas is relevant to some assets but less important to others. Figure 1 indicates that for A1 and A5, both the conditional market beta and price of market risk are equally important for the asset's risk premium. Consider a shift to investor beliefs from $\pi_{1}=0.90$ to $\pi_{2}=0.50$. The price of market risk, $\lambda_{m t}$, increases from $4.93 \%$ to $7.81 \%$, a change of $58 \%$. Likewise, asset A5 beta also change significantly, from 1.33 to 1.87, an increase of $41 \%$. The change in the asset $\mathrm{A} 1$ beta is also important but to the opposite direction, from 0.72 to 0.42 , a decrease of $42 \%$. The variation in the betas is less important than the variation in the price of market risk for the other assets, as we clearly observe from the plots.

\footnotetext{
${ }^{10}$ This rightward shift resulting from increases in risk aversion was also observed, in the single asset case, by Veronesi (1999).

${ }^{11}$ The price of market risk is often estimated by the sample mean of the market portfolio excess return.
} 
The above expressions are for all possible values of $\pi_{t} \in[0,1]$, but not all are equally likely. For the chosen parametrization, particularly $\lambda$ and $\mu$ that matches the U.S. business cycles, most of the mass of the $\pi_{t}$ distribution is above 0.50 , since the economy is most often in expansionary periods. Thus, on average, negative news about the economic conditions increases uncertainty while positive news decreases it. Consequently, the response of market betas ${ }^{12}$ to news is asymmetric due its (approximately) monotonic relation to uncertainty.

\section{Empirical Estimation of Betas}

In this section we estimate betas from stock returns data of firms traded in NYSE, Nasdaq and Amex markets. The objective is to verify if the patterns predicted by theory are also observed in the actual returns data. In particular, two of the theoretical implications will be tested. First, if the conditional betas of value and growth portfolios vary with investor beliefs and with investor uncertainty. As we have seen, value beta should be higher during periods of high uncertainty, but lower during periods of low uncertainty. On the other hand, growth beta should be lower during periods of high uncertainty, but higher during periods of low uncertainty. The second implication analyzed is whether conditional value and growth betas respond differently to positive and negative news about the economy. In this case, because negative news tends to increase uncertainty and positive news tends to reduce it, we expect value betas to be higher on negative news and lower on positive news. We expect the opposite behavior for growth betas.

\subsection{Conditional Betas and Uncertainty}

Before we proceed with the estimation of conditional betas using as state variables investor beliefs and uncertainty, we first discuss how to obtain proxies of such variables.

\subsubsection{Investor Beliefs and Uncertainty}

We follow Ozoguz (2009) and infer investor beliefs from market returns. This is done by fitting a two-state Markov-switching model to the conditional mean and variance of the market returns. The resulting filtered probability, $\hat{\pi}_{t+1}=\operatorname{Pr}_{t}\left(\right.$ state $\left._{t+1}=\mathrm{good}\right)$, is then used as a proxy for investor beliefs about the economy being in the good state. This state is identified as the state with longer

\footnotetext{
${ }^{12}$ And also the variance of returns and the covariance of returns with the market.
} 
duration.

The econometric specification of the two-state Markov-switching model follows Perez-Quiros and Timmermann (2000):

$$
\begin{aligned}
r_{m, t} & =c_{0, s_{t}}+c_{1, s_{t}} \text { Def }_{t-1}+c_{2, s_{t}} \text { Term }_{t-1}+c_{3, s_{t}} I_{t-1}+c_{4} \text { Yield }_{t-1}+\epsilon_{t} \\
\epsilon_{t} & \sim N\left(0, h_{S_{t}}\right), \ln \left(h_{S_{t}}\right)=c_{5, s_{t}}+c_{6, s_{t}} I_{t-1}
\end{aligned}
$$

where the explanatory variables of the conditional mean of market excess returns, $r_{m, t}$, are taken from the predictability literature: the dividend yield on the market portfolio $(Y$ ield $t)$, the spread on the yields of the U.S. 10 year and 1 year treasury bonds $\left(\right.$ Term $\left._{t}\right)$, the spread on the corporate bonds rated BAA and AAA by Moody's $\left(D e f_{t}\right)$, and the interest rate on the 3 months treasury bill $\left(I_{t}\right)$. The error term is assumed to be conditionally normal with a time-switching variance, which is an affine function of the short-run interest rates. The Markov-switching transition matrix parameters are specified as follows:

$$
\begin{aligned}
& p_{t}=\operatorname{Pr}\left(s_{t}=\text { good } \mid s_{t-1}=\text { good }, z_{t-1}\right)=\phi\left(d_{0}+d_{1} \Delta C L I_{t-1}\right) \\
& q_{t}=\operatorname{Pr}\left(s_{t}=\text { bad } \mid s_{t-1}=\text { bad }, z_{t-1}\right)=\phi\left(d_{0}+d_{2} \Delta C L I_{t-1}\right)
\end{aligned}
$$

where $p_{t}$ is the probability that at time $t$ the economy is in state $s_{t}=$ good, conditional on available information, $z_{t-1}$, and on the previous states being good. $1-p_{t}$ is then probability of switching to the bad state, $s_{t}=b a d$, conditional on the same information. Likewise, $q_{t}$ is the conditional probability that the economy remains in the bad state and $1-q_{t}$ that it shifts to the good state. The transition probabilities have a $t$ subscript because they are allowed to change over time according to the yearover-year changes of the variable $\Delta C L I_{t}$, a leading indicator of business cycles turning points. $\phi$ is the cumulative normal distribution and ensures that the probabilities $p_{t}$ and $q_{t}$ are numbers between 0 and 1.

The parameters estimated by maximum likelihood on the monthly sample from 1956 to 2010 are shown in Table 3. Our proxy of investor beliefs, the filtered probability shown in Figure 2 along with shaded areas denoting NBER recessions, captures reasonably well changes in the states of the economy. A measure for uncertainty is directly obtained from this proxy of beliefs by computing 
$h\left(\hat{\pi}_{t}\right)=\hat{\pi}_{t}\left(1-\hat{\pi}_{t}\right)$.

We also consider another proxy for investor uncertainty that is based on the implied volatility of option contracts on the market portfolio, the VIX index computed by the Chicago Board Options Exchange $(\mathrm{CBOE})^{13}$. This index is calculated from the $\mathrm{S} \& \mathrm{P} 500$ index options and measures the risk-neutral variance implied by the contracts, with a fixed 30-day maturity. This uncertainty proxy based on option prices can be justified theoretically, since the market's risk neutral expected volatility is positively and monotonically related to uncertainty (derivation of risk neutral moments is available upon request). The advantage of this proxy of uncertainty is that it is model-free, and can be obtained directly from prices of traded contracts. The disadvantage is the limited sample size; monthly data is only available since 1990.

The choice of VIX as a proxy is also motivated by the empirical evidence pointing to the predictive power of the VIX index over stock returns. Bollerslev et al. (2009) have shown that the difference between implied and realized volatility on the market portfolio, what they call the variance risk premium, is able to explain future market returns, particularly at the quarterly frequency, that cannot be accounted for by the traditional predicting variables, such as the price-earnings ratio and default spread. However, the theoretical justification for the predicting properties of the riskneutral variance is different than the one suggested here. The authors introduce time-variation in the volatility consumption process, i.e. the volatility of consumption volatility, which is equivalent, in their endowment economy, to the volatility of cash-flow volatility. In our context, risk-neutral variance, like other variables of interest, is a function of investor uncertainty. And because the risk-neutral variance is also an exact monotonic function of uncertainty, it works as an appropriate proxy for the unobserved investor uncertainty.

Table 3 shows the descriptive statistics of the proxies for belief and uncertainty. The two proxies for uncertainty are correlated only to a certain extent.

\subsubsection{Conditional Betas}

We have seen in Figure 1 that our model predicts conditional betas to be non-linearly related to investor beliefs. In order to assess if this is actually observed in the data, we propose the following

\footnotetext{
${ }^{13}$ http://www.cboe.com/micro/VIX/historical.aspx
} 
specification for conditional market betas:

$$
\beta_{m i, t}=a_{1, i}+a_{2, i} \hat{\pi}_{t}+a_{3, i} \hat{\pi}_{t}^{2}
$$

for $i=1, \ldots, N$, where $\hat{\pi}_{t}$ is the proxy for investor beliefs described above, and $a_{1, i}, a_{2, i}$ and $a_{3, i}$ are the parameters to be estimated from data. Assuming observed returns have the factor structure, $R_{i, t}=\alpha_{i}+\beta_{m i, t} R_{m, t}+\epsilon_{i, t}, i=1, \ldots, N$, we estimate all the parameters jointly by Generalized Method of Moments (GMM), using the following moment restrictions:

$$
E\left\{\left[R_{i, t}-\alpha_{i}-\left(a_{1, i}+a_{2, i} \hat{\pi}_{t}+a_{3, i} \hat{\pi}_{t}^{2}\right) R_{m, t}\right] \otimes Z_{t}\right\}=\mathbf{0}
$$

where the instruments are $Z_{t}=\left[\begin{array}{llll}1 & R_{m, t} & \hat{\pi}_{t} R_{m, t} & \hat{\pi}_{t}^{2} R_{m, t}\end{array}\right]^{\prime}$. In this specification, the system is exactly identified, with same number of parameters and restrictions, $N \times 4$.

We first use the same dataset that calibrated the model in Section 3. This dataset consists of monthly excess returns from 1956 to 2010 of five book-to-market sorted portfolios and the valueweighted market portfolio from the Center for Research in Security Prices (CRSP). In the top panel of Table 4, the estimated parameters of the specification (6) have the predicted signs, but are statistically insignificant. The estimated functional forms depicted in Figure 3 indicate that the conditional beta of the low book-to-market portfolio decreases on uncertainty whereas that of high book-to-market portfolio increases on uncertainty. We also observe that portfolios with similar book-to-market ratios share similar patterns; the beta of the fourth quintile (4 Qnt) also increases on uncertainty, and the beta of the second quintile (2 Qnt) decreases on uncertainty. However, the variation in the conditional betas, particularly on the two extreme portfolios, the value and growth ones, does not have the amplitude suggested by the theory.

We also analyze the following dynamics for market betas:

$$
\beta_{m i, t}=b_{1, i}+b_{2, i} U C_{t}
$$

where $U C_{t}$ is the proxy for uncertainty. We use two proxies for uncertainty, $\hat{\pi}_{t}\left(1-\hat{\pi}_{t}\right)$ and $V I X_{t}$, to assess to which extent the results depend on the proxy chosen. As before, we estimate the parameters 
by GMM to obtain robust covariances by imposing the following set of moment conditions:

$$
E\left\{\left[R_{i, t}-\alpha_{i}-\left(a_{4, i}+a_{5, i} U C_{t}\right) R_{m, t}\right] \otimes Z_{t}\right\}=\mathbf{0}
$$

where the instruments are $Z_{t}=\left[\begin{array}{ccc}1 & R_{m, t} & U C_{t} R_{m, t}\end{array}\right]^{\prime}$. As before, the system is exactly identified, with $N \times 3$ parameters and moment restrictions.

The second, third and fourth panels of Table 4 confirm the predicted patterns about betas and uncertainty. For two different proxies of uncertainty, $\hat{\pi}_{t}\left(1-\hat{\pi}_{t}\right)$ and $V I X_{t}$, and two different sample sizes, from March 1956 to December 2010 and January 1990 to December 2010, the estimated coefficients $a_{5, i}$ are generally positive for value portfolios and negative for growth portfolios. Furthermore, for the model-free proxy, $V I X_{t}$, the coefficients are now significantly different than zero.

Similar results arise when we use decile sorts. Tables 5 and 6 show that the lowest deciles (growth portfolios) tend to have lower betas during periods of high uncertainty. The highest deciles (value portfolios), however, tend to have higher betas on periods of high uncertainty. In the case of Table 6, the coefficients are statistically different than zero (at 10\% level).

In this section we have seen how the dynamics of risk differs across portfolios. Our empirical findings suggest that market betas of value and growth portfolio do respond differently to changes in uncertainty, as predicted by our theory. Both the more flexible functional form estimated from (6) and the affine function of uncertainty estimated from (7) result in value betas increasing on uncertainty and growth betas decreasing on uncertainty. The qualitative results remain when another proxy for uncertainty is used, $V I X_{t}$, but now with statistical significance. The amplitude of the variation in conditional betas, however, is smaller than the one predicted by the model. Furthermore, a value premium still remains as can be observed by the significance of the intercepts, $\alpha_{i}$. Thus, despite correctly capturing the model's main implications regarding the dynamics of market betas, and thus going on the direction of solving the value premium, the proposed estimators may not completely capture the cross-section variation in expected returns. This agrees with Petkova and Zhang (2005) that, despite conditional betas going in the right direction in explaining the value premium puzzle, they cannot completely explain it. This point was also made by Lewellen and Nagel (2006). 


\subsection{Conditional Betas and News}

In this section we investigate if market betas differ conditionally on the sign of news. As a proxy for news, we will use normalized market returns. For this purpose, we follow Ang and Chen (2002), and define upside beta, $\beta_{+}(c)$, and downside beta, $\beta_{-}(c)$, in the following way:

$$
\begin{aligned}
& \beta_{+}(c)=\frac{\operatorname{cov}\left(\tilde{r}_{i, t}, \tilde{r}_{m, t} \mid \tilde{r}_{m, t}>c\right)}{\operatorname{var}\left(\tilde{r}_{m, t} \mid \tilde{r}_{m, t}>c\right)} \\
& \beta_{-}(c)=\frac{\operatorname{cov}\left(\tilde{r}_{i, t}, \tilde{r}_{m, t} \mid \tilde{r}_{m, t}<-c\right)}{\operatorname{var}\left(\tilde{r}_{m, t} \mid \tilde{r}_{m, t}<-c\right)}
\end{aligned}
$$

where $c$ is the threshold. The return on portfolio $i, \tilde{r}_{i, t}$, and the return on the market portfolio, $\tilde{r}_{m, t}$, are normalized to have zero mean and unit variance, to allow the thresholds across portfolios to be comparable. The thresholds will take values between 0 and 1.5. In order to have a larger dataset, we increase the number of observations by working with weekly returns as opposed to the monthly frequency used in previous sections. Also, we use here the decile sort on book-to-market.

Figure 5 shows different asymmetric patterns across book-to-market sorted portfolios. The downside beta of the value portfolio, BE10, is typically higher than the upside betas across all thresholds. On the other hand, the upside betas of growth portfolios are slightly higher that the corresponding downside betas. The dynamics on the deciles between the lowest and highest bookto-market, BE3, BE5 and BE8, confirms the opposing patterns of value and growth betas.

In order to see if these results are statistically relevant, we need a formal test to verify if such asymmetries persist after accounting for sample variation. For this task, we use the test suggested by Hong et al. (2007). The advantages of the test are that it is model-free and relatively simple to compute. The null hypothesis of symmetric betas across thresholds, $c$, is tested against no asymmetries for some $c$ :

$$
\begin{aligned}
& H_{0}: \quad \beta_{+}(c)=\beta_{-}(c), \text { for all } c \geq 0 \\
& H_{a}: \quad \beta_{+}(c) \neq \beta_{-}(c), \text { for some } c \geq 0
\end{aligned}
$$

To compute a statistic to test such hypothesis, let $n$ thresholds $c_{1}, \ldots, c_{n}$ and define the $(n \times 1)$ 
vector $\beta_{+}-\beta_{-}=\left[\beta_{+}\left(c_{1}\right)-\beta_{-}\left(c_{1}\right), \ldots, \beta_{+}\left(c_{n}\right)-\beta_{-}\left(c_{n}\right)\right]^{\prime}$. The test statistic is the following:

$$
J_{\beta}=T\left(\beta_{+}-\beta_{-}\right)^{\prime} \hat{\Psi}^{-1}\left(\beta_{+}-\beta_{-}\right)
$$

where $\hat{\Psi}=\sum_{l=1-T}^{T-1} k(l / p) \hat{\gamma}_{l}$ is a weighted sum of $\hat{\gamma}_{l}$, an $N \times N$ matrix with $(i, j)-t h$ element given by $\hat{\gamma}_{l}\left(c_{i}, c_{j}\right)=T^{-1} \sum_{t=|l|+1}^{T-1} \hat{\xi}_{t}\left(c_{i}\right) \hat{\xi}_{t-|l|}\left(c_{j}\right)$ and

$$
\begin{aligned}
\hat{\xi}_{t}\left(c_{i}\right)= & \frac{T-T_{+}}{T_{+}}\left[\frac{\left(\tilde{r}_{j, t}-\mu_{+j}\left(c_{i}\right)\right)\left(\tilde{r}_{m, t}-\mu_{+m}\left(c_{i}\right)\right)}{\sigma_{+m}^{2}\left(c_{i}\right)}-\beta_{+}\left(c_{i}\right)\right] 1\left(\tilde{r}_{m, t}>c_{i}\right) \\
& -\frac{T-T_{-}}{T_{-}}\left[\frac{\left(\tilde{r}_{j, t}-\mu_{-j}\left(c_{i}\right)\right)\left(\tilde{r}_{m, t}-\mu_{-m}\left(c_{i}\right)\right)}{\sigma_{-m}^{2}\left(c_{i}\right)}-\beta_{-}\left(c_{i}\right)\right] 1\left(\tilde{r}_{m, t}<-c_{i}\right)
\end{aligned}
$$

where $T_{+}$is the number of observations when market returns are above $c_{i}, \mu_{+}\left(c_{i}\right)$ and $\sigma_{+}^{2}\left(c_{i}\right)$ are the mean and variance conditional on market returns being above $c_{i}$. Define likewise the variables below the $-c_{i}$ threshold. The statistic is asymptotically chi-square distributed with $n$ degrees of freedom, $J_{\beta} \sim \chi_{n}^{2}$.

Table 7 shows the results of the asymmetry tests on the betas conditional on market returns being above and below $c$ 's. The tests are conducted for thresholds, $c=[0,0.1, \ldots, 1.4,1.5]$, for each of the 10 portfolios sorted by book-to-market. The averages of differences in betas, $\overline{\beta_{+}-\beta_{-}}$, show the monotonic pattern predicted by our theory. The p-value of the $J_{\beta}$ statistics indicates that this difference is significant only on the extreme portfolios.

\section{Conclusion}

In this paper we have found new theoretical implications for market betas. In particular, we have shown that investor uncertainty about the asset's cash-flow distribution can result in timevarying market betas. Furthermore, we have shown that assets that are susceptible to changes in the economic conditions, should be riskier during such periods. In a calibration exercise, we have found that value portfolios are one of such assets. That is, the market beta of value portfolios tend to become higher during periods of high uncertainty. On the other hand, growth portfolios tend to become riskier during periods of low uncertainty. This result points to a counter-cyclical value premium, a result found empirically by Petkova and Zhang (2005). The opposing cash-flow structure of growth and value portfolios found were also in line with Koijen et al. (2012). 
The theoretical expressions for conditional betas were largely confirmed empirically by our estimators of conditional betas using U.S. stock data. As a further development of our results, other measures of investor uncertainty will be investigated as to improve the empirical evidence of the model's predictions. 


\section{References}

Adrian, T. and F. Franzoni (2009). Learning about beta: Time-varying factor loadings, expected returns, and the conditional capm. Journal of Empirical Finance In Press, Corrected Proof, -.

Andersen, T., T. Bollerslev, F. Diebold, and G. Wu (2006). Realized Beta: Persistence and Predictability, Volume 20 of Advances in Econometrics, pp. 1-39. in T. Fomby and D. Terrell.

Ang, A. and J. Chen (2002). Asymmetric correlations of equity portfolios. Journal of Financial Economics 63(3), $443-494$.

Ang, A. and J. Chen (2007). Capm over the long run: 1926-2001. Journal of Empirical Finance $14(1), 1-40$.

Ang, A., J. Chen, and Y. Xing (2006). Downside risk. The Review of Financial Studies 19(4), $1191-1239$.

Bansal, R., R. F. Dittmar, and C. T. Lundblad (2005). Consumption, dividends, and the cross section of equity returns. The Journal of Finance 60(4), 1639-1672.

Berk, J. B., R. C. Green, and V. Naik (1999). Optimal investment, growth options, and security returns. The Journal of Finance 54(5), 1553-1607.

Bollerslev, T., R. F. Engle, and J. M. Wooldridge (1988, February). A capital asset pricing model with time varying covariances. Journal of Political Economy 96(1), 116-131.

Bollerslev, T., G. Tauchen, and H. Zhou (2009). Expected stock returns and variance risk premia. Review of Financial Studies 22(11), 4463-4492.

Cochrane, J. H. and M. Piazzesi (2005). Bond risk premia. The American Economic Review 95(1), pp. $138-160$.

Fama, E. F. and K. R. French (1993). Common risk factors in the returns on stocks and bonds. Journal of Financial Economics 33, 3-56.

Fama, E. F. and J. MacBeth (1973, May-June). Risk, return and equilibrium: Empirical tests. Journal of Political Economy 81, 607-636. 
Gomes, J., L. Kogan, and L. Zhang (2003). Equilibrium cross section of returns. The Journal of Political Economy 111(4), 693-732.

Harvey, C. R. (1989). Time-varying conditional covariances in tests of asset pricing models. Journal of Financial Economics 24(2), 289 - 317.

Harvey, C. R. and C. Kirby (1996). 2 instrumental variables estimation of conditional beta pricing models. In G. Maddala and C. Rao (Eds.), Statistical Methods in Finance, Volume 14 of Handbook of Statistics, pp. 35 - 60. Elsevier.

Hong, Y., J. Tu, and G. Zhou (2007). Asymmetries in stock returns: Statistical tests and economic evaluation. Review of Financial Studies 20(5), 1547-1581.

Jagannathan, R. and Z. Wang (1996, March). The CAPM is alive and well. Journal of Finance $51(1), 3-53$.

Koijen, R. S. J., H. Lustig, and S. van Nieuwerburgh (2012). The Cross-Section and Time Series of Stock and Bond Returns.

Lewellen, J. and S. Nagel (2006). The conditional capm does not explain asset-pricing anomalies. Journal of Financial Economics 82(2), 289 - 314.

Lipster, R. and A. Shiryaev (2001). Statistics of Random Processes: Applications. Applications of mathematics. Springer.

Merton, R. C. (1973). An intertemporal capital asset pricing model. Econometrica 41(5), 867-887.

Merton, R. C. (1980). On estimating the expected return on the market : An exploratory investigation. Journal of Financial Economics 8(4), 323 - 361.

Ozoguz, A. (2009). Good times or bad times investors' uncertainty and stock returns. Review of Financial Studies 22, 4377-4422(46).

Perez-Quiros, G. and A. Timmermann (2000). Firm size and cyclical variations in stock returns. The Journal of Finance 55(3), 1229-1262.

Petkova, R. and L. Zhang (2005). Is value riskier than growth? Journal of Financial Economics 78(1), $187-202$. 
Ribeiro, R. and P. Veronesi (2002). The excess co-movement of international stock markets in bad times: A rational expectations equilibrium model.

Santos, J. and P. Veronesi (2004). Conditional Betas. SSRN eLibrary.

Veronesi, P. (1999). Stock market overreactions to bad news in good times: a rational expectations equilibrium model. Review of Financial Studies 12(5), 975-1007.

Veronesi, P. (2004). The peso problem hypothesis and stock market returns. Journal of Economic Dynamics and Control 28(4), $707-725$.

Zhang, L. (2005). The value premium. The Journal of Finance 60(1), 67-103. 


\section{A The Model}

In this appendix we solve the investor problem and derive the asset pricing equations. This model was also derived by Ribeiro and Veronesi (2002). The problem of the representative investor has two parts. In the first part, the investor optimally infer the conditional means of the cash-flow processes. In the second part, the investor maximize the utility function subject to the intertemporal budget constraint, with choice variables consumption, $\left\{c_{t}\right\}$, and demand for assets, $\left\{X_{t}\right\}, X_{t}=\left[x_{1 t} \ldots x_{n t}\right]^{\prime}$. The maximization is solved using the Bellman-Hamilton-Jacobi equation with two state variables, wealth, $W_{t}$, and the belief $\pi_{t}$.

Recall the assumptions about the available assets in this economy. There are $n$ risky assets in this economy that pay a continuous stream of cash-flows: $d D_{t}=\theta_{t} d t+\Phi d \xi_{t}$. The random vector $\theta_{t}$, is not observed by the investor, who only knows the values it can take, $\left[\theta_{G}, \theta_{B}\right]$, and that it follows a 2 state Markov process with the following infinitesimal transition matrix:

$$
M=\left[\begin{array}{cc}
-\lambda & \lambda \\
\mu & -\mu
\end{array}\right]
$$

with $\lambda=\operatorname{Prob}\left(\theta_{t+d t}=\theta_{B} \mid \theta_{t}=\theta_{G}\right)$ and $\mu=\operatorname{Prob}\left(\theta_{t+d t}=\theta_{G} \mid \theta_{t}=\theta_{B}\right)$. The lemma (1) shows that the investor's optimal beliefs about the state of the economy conditional on $\mathcal{F}_{t}=\sigma\left(D_{\tau}, \tau<t\right)$ can be represented by the following stochastic differential equation:

$$
d \pi_{t}=(\lambda+\mu)\left(\pi_{s}-\pi_{t}\right) d t+\pi_{t}\left(1-\pi_{t}\right) \Delta \theta^{\prime} \Phi^{\prime-1} d v_{t}
$$

Under this incomplete information set, $\mathcal{F}_{t}$, cash-flows can be written as $d D_{t}=\alpha_{D t} d t+\Phi d \mathbf{v}_{t}$, where $\alpha_{D t}=\left[\alpha_{1 D, t}, \ldots, \alpha_{n D, t}\right]^{\prime}$ and $\alpha_{i D, t} \equiv \theta_{i G} \pi_{t}+\theta_{i B}\left(1-\pi_{t}\right)$.

With the optimal beliefs already defined, we now turn to the utility maximization problem. First, since the risk free is inelastically supplied, the budget constraint is given by:

$$
\begin{aligned}
d W_{t} & =X_{t}^{\prime}\left(d P_{t}+D_{t} d t\right)+\left(W_{t}-X_{t}^{\prime} P_{t}\right) r d t-c_{t} d t \\
& =X_{t}^{\prime}\left(d P_{t}+D_{t} d t-r P_{t} d t\right)+\left(W_{t} r-c_{t}\right) d t
\end{aligned}
$$


where $X_{t}=\left[\begin{array}{lll}x_{1 t} & \ldots & x_{n t}\end{array}\right]^{\prime}$ are the demand for asset shares and $P_{t}=\left[P_{1 t} \ldots P_{n t}\right]$ the asset prices.

As in Veronesi (1999), first conjecture a functional form for prices and then find are parameters that solve the problem. The conjectured form is linear in $D_{t}$ but possibly non-linear in $\pi_{t}$, through the function $S_{i}$ :

$$
P_{i t}=p_{i 0}+p_{i \pi} \pi_{t}+p_{i D} D_{i t}+p_{i 1}+S_{i}\left(\pi_{t}\right)
$$

and by Ito's lemma we obtain:

$$
\begin{gathered}
d P_{i t}=\alpha_{i p} d t+\sigma_{i p} d v_{t} \quad i=1, \ldots, n \\
\alpha_{i p}=\left(p_{i \pi}+S_{i}^{\prime}\left(\pi_{t}\right)\right) \alpha_{\pi}+p_{i D} m_{i t}+\frac{1}{2} S_{i}^{\prime \prime}\left(\pi_{t}\right) h\left(\pi_{t}\right)^{2} H \\
\sigma_{i p}=h\left(\pi_{t}\right)\left(p_{i \pi}+S_{i}^{\prime}\left(\pi_{t}\right)\right) \Delta \theta^{\prime} \Phi^{\prime-1}+p_{i D} \sigma_{i}
\end{gathered}
$$

with the simplifying notation $\alpha_{\pi} \equiv(\lambda+\mu)\left(\pi_{s}-\pi_{t}\right), h\left(\pi_{t}\right) \equiv \pi_{t}\left(1-\pi_{t}\right)$ and $H \equiv \Delta \theta^{\prime} \Sigma^{-1} \Delta \theta$. Furthermore, denote the vector of price changes by: $d P_{t}=\alpha_{p} d t+\Phi_{p} d v_{t}$, where $\alpha_{p}=\left[\alpha_{1 p}, \ldots, \alpha_{n p}\right]^{\prime}$ and $\Phi_{p}$ is a $n \times n$ matrix that stacks the row vectors $\sigma_{i p}$, and $\Sigma_{p}=\Phi_{p} \Phi_{p}^{\prime}$. Substitute the conjecture prices into the budget constraint to obtain:

$$
d W_{t}=\left[X_{t}^{\prime}\left(\alpha_{p}+D_{t}-r P_{t}\right)+W_{t} r-c_{t}\right] d t+X_{t}^{\prime} \Phi_{p} d v_{t}
$$

\section{Risk Neutral Prices}

The parameters $p_{0}=\left[p_{10}, \ldots, p_{n 0}\right]^{\prime}, p_{\pi}=\left[p_{1 \pi}, \ldots, p_{n \pi}\right]^{\prime}$ and $p_{D}=\left[p_{1 D}, \ldots, p_{n D}\right]^{\prime}$ are found by solving for risk neutral prices, $P_{i, t}^{R N}$ :

$$
P_{i, t}^{R N} \equiv E_{t}\left[\int_{0}^{\infty} e^{-r s} D_{i, t+s} d s\right]=\int_{0}^{\infty} e^{-r s} E_{t}\left[D_{i, t+s}\right] d s
$$

where the equality follows from Foubini's theorem. Since, $D_{i, t+s}=D_{i t}+\int_{0}^{s} \alpha_{i D, t+\tau} d \tau+\sigma_{i}\left(v_{t+s}-v_{t}\right)$, the only conditional expectation that matters is $\int_{0}^{s} E_{t}\left[\alpha_{i D, t+\tau}\right] d \tau$. For this, we need the eigendecom- 
position of the infinitesimal transition matrix $M$ to compute the transition matrix over $\tau$ periods. The eigenvalues of $M$ are 0 and $-(\lambda+\mu)$ with corresponding eigenvectors $[11]^{\prime}$ and $\left[-1 \frac{\mu}{\lambda}\right]^{\prime}$. The transition matrix over $\tau$ is:

$$
\begin{aligned}
P(\tau) & =\left[\begin{array}{cc}
1 & -1 \\
1 & \frac{\mu}{\lambda}
\end{array}\right]\left[\begin{array}{cc}
e^{0 \tau} & 0 \\
0 & e^{-(\lambda+\mu) \tau}
\end{array}\right]\left[\begin{array}{cc}
1 & -1 \\
1 & \frac{\mu}{\lambda}
\end{array}\right] \\
& =\frac{1}{(\lambda+\mu)}\left[\begin{array}{cc}
\mu+\lambda e^{-(\lambda+\mu) \tau} & \lambda-\lambda e^{-(\lambda+\mu) \tau} \\
\mu-\mu e^{-(\lambda+\mu) \tau} & \lambda+\mu e^{-(\lambda+\mu) \tau}
\end{array}\right]
\end{aligned}
$$

and so $E_{t}\left[\alpha_{i D, t+\tau}\right]=\left[\pi_{t} 1-\pi_{t}\right] P(\tau)\left[\theta_{i G} \theta_{i B}\right]^{\prime}=\theta_{i s}+\Delta \theta_{i}\left(\pi_{t}-\pi_{s}\right) e^{-(\lambda+\mu) \tau}$, where $\pi_{s}=\mu /(\mu+\lambda)$ and $\theta_{i s}=\theta_{i G} \pi_{s}+\theta_{i B}\left(1-\pi_{s}\right)$. Now, the conditional expectation of cash-flows are:

$$
\begin{aligned}
E_{t}\left[D_{i, t+u}\right] & =D_{i t}+\int_{0}^{s}\left[\theta_{i s}+\Delta \theta_{i}\left(\pi_{t}-\pi_{s}\right) e^{-(\lambda+\mu) \tau}\right] d \tau \\
& =D_{i t}+\theta_{i s} s+\frac{\Delta \theta_{i}\left(\pi_{s}-\pi_{t}\right)}{\lambda+\mu}\left[e^{-(\lambda+\mu) s}-1\right]
\end{aligned}
$$

and finally, risk neutral prices are found by continuously discounting expected dividends at the risk free rate:

$$
\begin{aligned}
P_{i, t}^{R N} & =\int_{0}^{\infty} e^{-r s}\left[D_{i t}+\theta_{i s} s+\frac{\Delta \theta_{i}\left(\pi_{s}-\pi_{t}\right)}{\lambda+\mu}\left[e^{-(\lambda+\mu) s}-1\right]\right] d s \\
& =\frac{D_{i t}}{r}+\frac{\theta_{i s}}{r^{2}}-\frac{\Delta \theta_{i}\left(\pi_{s}-\pi_{t}\right)}{\lambda+\mu}\left[\frac{1}{r}-\frac{1}{(\lambda+\mu+r)}\right] \\
& =p_{i 0}+p_{i \pi} \pi_{t}+p_{i D} D_{i t}
\end{aligned}
$$

where

$$
\begin{aligned}
p_{i 0} & =\frac{\theta_{i B}}{r^{2}}+\frac{\Delta \theta_{i} \mu}{r^{2}(\lambda+\mu+r)} \\
p_{i \pi} & =\frac{\Delta \theta_{i}}{r(\lambda+\mu+r)} \\
p_{i D} & =\frac{1}{r}
\end{aligned}
$$




\section{Risk Averse Prices}

To solve for the risk aversion case, we need to solve the investor problem:

$$
\begin{aligned}
J\left(W_{t}, \pi_{t}, t\right) & =\max _{\left\{c_{t}, X_{t}\right\}} E\left[\int_{0}^{\infty} U\left(c_{s}, s\right) d s\right] \\
\text { s.t. } d W_{t} & =\left[X_{t}^{\prime}\left(\alpha_{p}+D_{t}-r P_{t}\right)+W_{t} r-c_{t}\right] d t+X_{t}^{\prime} \Phi_{p} d v_{t} \text { (Budget Constraint) } \\
X_{t} & =\left[\omega_{1} \ldots \omega_{n}\right]^{\prime} \equiv \omega \quad \text { (Market Clearing) }
\end{aligned}
$$

This problem is solved using the Hamilton-Bellman-Jacobi equation:

$$
\begin{aligned}
0= & \max _{c_{t}, X_{t}}\left[U\left(c_{t}, t\right)+J_{t}+J_{W} \frac{E_{t}\left[d W_{t}\right]}{d t}+J_{\pi} \frac{E_{t}\left[d \pi_{t}\right]}{d t}+\frac{1}{2} J_{W W} \frac{E_{t}\left[d W_{t}^{2}\right]}{d t}\right. \\
& \left.+\frac{1}{2} J_{\pi \pi} \frac{E_{t}\left[d \pi_{t}^{2}\right]}{d t}+J_{W \pi} \frac{E_{t}\left[d W_{t} d \pi_{t}\right]}{d t}\right]
\end{aligned}
$$

where we have that:

$$
\begin{aligned}
E_{t}\left[d W_{t}\right] & =\left[X_{t}^{\prime}\left(\alpha_{p}+D_{t}-r P_{t}\right)+W_{t} r-c_{t}\right] d t \\
E_{t}\left[d W_{t}^{2}\right] & =X_{t}^{\prime} \Sigma_{p} X_{t} d t \\
E_{t}\left[d \pi_{t}\right] & =\alpha_{\pi} d t \\
E_{t}\left[d \pi_{t}^{2}\right] & =h\left(\pi_{t}\right)^{2} H d t \\
E_{t}\left[d W_{t} d \pi_{t}\right] & =X^{\prime} \Phi_{p} \sigma_{\pi}^{\prime} d t
\end{aligned}
$$

A solution to problem, $c_{t}^{*}$ and $X_{t}^{*}$, satisfy the first order conditions:

$$
\begin{aligned}
& 0=U_{c}\left(c_{t}^{*}, t\right)-J_{W} \\
& 0=J_{W}\left(\alpha_{p}+D_{t}-r P_{t}\right)+J_{W W} \Sigma_{p} X_{t}+J_{W \pi} \Phi_{p} \sigma_{\pi}^{\prime}
\end{aligned}
$$

In order to advance, we have to conjecture a functional form for the value function. Following the univariate model of Veronesi (1999), we set $J\left(W_{t}, \pi_{t}, t\right)=-\exp \left(-\rho t-r \gamma W_{t}-g\left(\pi_{t}\right)-\beta\right)$ where 
$g\left(\pi_{t}\right)$ is a function to be determined and $\beta$ a constant to be defined. Substituting the partial derivatives of the conjecture value function and of the utility function, $U\left(c_{t}, t\right)=-\exp \left(-\rho t-\gamma c_{t}\right)$, on the first order conditions we obtain:

$$
\begin{aligned}
c_{t}^{*} & =\frac{1}{\gamma}\left(r \gamma W_{t}+g\left(\pi_{t}\right)+\beta-\ln (r)\right) \\
X_{t}^{*} & =\frac{1}{r \gamma} \Sigma_{p}^{-1}\left(\alpha_{p}+D_{t}-r P_{t}\right)-\frac{g^{\prime}\left(\pi_{t}\right)}{r \gamma} \Sigma_{p}^{-1} \Phi_{p} \sigma_{\pi}^{\prime}
\end{aligned}
$$

We have an extra equation that will help to identify the problem. Evaluate the HJB equation at the maximum and set it equal to zero:

$$
\begin{aligned}
0= & -\exp \left(-\rho t-\gamma c_{t}^{*}\right)-\rho J-r \gamma J\left[X_{t}^{* \prime}\left(\alpha_{p}+D_{t}-r P_{t}\right)+W_{t} r-c_{t}\right]-g^{\prime}\left(\pi_{t}\right) J \alpha_{\pi}+ \\
& \frac{1}{2}(r \gamma)^{2} J X_{t}^{* \prime} \Sigma_{p} X_{t}^{*}+\frac{1}{2}\left(-g^{\prime \prime}\left(\pi_{t}\right)+g\left(\pi_{t}\right)^{2}\right) J h\left(\pi_{t}\right)^{2} H+r \gamma g^{\prime}\left(\pi_{t}\right) J X^{* \prime} \Phi_{p} \sigma_{\pi}^{\prime}
\end{aligned}
$$

Before we proceed, we can simplify the expression for $\alpha_{p}+D_{t}-r P_{t}$ by substituting the parameters that were obtained for the risk neutral price, $p_{i 0}, p_{i \pi}$ and $p_{i D}$.

$$
\begin{aligned}
\alpha_{i p}+D_{i t}-r P_{i t}= & \left(p_{i \pi}+S_{i}^{\prime}\left(\pi_{t}\right)\right) \alpha_{\pi}+p_{i D} D_{i t}+\frac{1}{2} S_{i}^{\prime \prime}\left(\pi_{t}\right) h\left(\pi_{t}\right)^{2} H+D_{i t} \\
& -r\left(p_{i 0}+p_{i \pi} \pi_{t}+p_{i D} D_{i t}+p_{i 1}+S_{i}\left(\pi_{t}\right)\right) \\
= & -r p_{i 1}-r S_{i}\left(\pi_{t}\right)+S_{i}^{\prime}\left(\pi_{t}\right) \alpha_{\pi}+\frac{1}{2} S_{i}^{\prime \prime}\left(\pi_{t}\right) H h\left(\pi_{t}\right)^{2}
\end{aligned}
$$

Take the above simplification, the expression for $c_{t}^{*}$ from the first order condition (9) and the market clearing $X_{t}^{*}=\omega$ and substitute them in the equality (11) to get:

$$
\begin{aligned}
0= & r-\rho-r \gamma\left[\omega^{\prime}\left(-r p_{1}-r S\left(\pi_{t}\right)+S^{\prime}\left(\pi_{t}\right) \alpha_{\pi}+\frac{1}{2} S^{\prime \prime}\left(\pi_{t}\right) H h\left(\pi_{t}\right)^{2}\right)-\frac{g\left(\pi_{t}\right)}{\gamma}-\frac{\beta}{\gamma}+\frac{\ln (r)}{\gamma}\right]+ \\
& r \gamma g^{\prime}\left(\pi_{t}\right)\left[\omega^{\prime}\left(h\left(\pi_{t}\right)\left(p_{\pi}+S^{\prime}\left(\pi_{t}\right)\right) \Delta \theta^{\prime} \Phi^{\prime-1}+p_{D} \Phi\right)\left(\Phi^{-1} \Delta \theta h\left(\pi_{t}\right)\right)\right]+ \\
& \frac{1}{2}(r \gamma)^{2}\left[\omega^{\prime}\left(h\left(\pi_{t}\right)\left(p_{\pi}+S^{\prime}\left(\pi_{t}\right)\right) \Delta \theta^{\prime} \Phi^{\prime-1}+p_{D} \Phi\right)\left(h\left(\pi_{t}\right)\left(p_{\pi}+S^{\prime}\left(\pi_{t}\right)\right) \Delta \theta^{\prime} \Phi^{\prime-1}+p_{D} \Phi\right)^{\prime} \omega\right]+ \\
& \frac{1}{2}\left(-g^{\prime \prime}\left(\pi_{t}\right)+g\left(\pi_{t}\right)^{2}\right) h\left(\pi_{t}\right)^{2} H-g^{\prime}\left(\pi_{t}\right) \alpha_{\pi}
\end{aligned}
$$

where we have used the notation $p_{m 1} \equiv \omega^{\prime} p_{1}, p_{m \pi} \equiv \omega^{\prime} p_{\pi}, \Delta \theta_{m} \equiv \omega^{\prime} \Delta \theta$. Also, let $\sigma_{\omega}^{2} \equiv \omega^{\prime} \Sigma \omega$ and $\sigma_{i \omega} \equiv e_{i}^{\prime} \Sigma \omega$ denote the variance of the market portfolio cash-flow and covariance of the market 
and asset $i$ cash-flows, where $e_{i}$ is a vector with zeros and one the $i t h$ position. Note that in the above equation the $S=\left[S_{1}, \ldots, S_{n}\right]^{\prime}$ vector of functions is multiplied by the market clearing vector $\omega$ and so the equality only depends on $S_{m} \equiv \omega^{\prime} S$. After some simplifications and substituting $f\left(\pi_{t}\right)=g\left(\pi_{t}\right)+r \gamma S_{m}\left(\pi_{t}\right)$ we get the following nonlinear differential equation for $f\left(\pi_{t}\right)$ :

$$
0=-f^{\prime \prime}\left(\pi_{t}\right) Q_{3}\left(\pi_{t}\right)+\left(f^{\prime}\left(\pi_{t}\right)\right)^{2} Q_{3}\left(\pi_{t}\right)+f^{\prime}\left(\pi_{t}\right) Q_{2}\left(\pi_{t}\right)+f^{\prime}\left(\pi_{t}\right) r+Q_{0}\left(\pi_{t}\right)
$$

where

$$
\begin{aligned}
Q_{3}\left(\pi_{t}\right) & =\frac{1}{2} h^{2}\left(\pi_{t}\right) H \\
Q_{2}\left(\pi_{t}\right) & =\gamma h\left(\pi_{t}\right) \Delta \theta_{m}+r \gamma h\left(\pi_{t}\right)^{2} H \frac{\Delta \theta_{m}}{r(r+\mu+\lambda)}-\alpha_{\pi} \\
Q_{0}\left(\pi_{t}\right) & =\frac{1}{2} H\left(\frac{r \gamma h\left(\pi_{t}\right) \Delta \theta_{m}}{r(r+\mu+\lambda)}\right)^{2}+r \gamma^{2} h\left(\pi_{t}\right) \frac{\Delta \theta_{m}^{2}}{r(r+\mu+\lambda)}
\end{aligned}
$$

where some extra terms in $Q_{0}\left(\pi_{t}\right)$ were eliminated after choosing appropriately the parameters $\beta$ and $p_{1}$ :

$$
\begin{aligned}
\beta & =\frac{\rho}{r}+\ln (r)+\frac{\gamma^{2}}{2 r} \sigma_{\omega}^{2}-1 \\
p_{i 1} & =-\frac{\gamma}{r^{2}} e_{i}^{\prime} \Sigma \omega
\end{aligned}
$$

which in vector notation is $p_{1}=-\frac{\gamma}{r^{2}} \Sigma \omega$. This non-linear differential equation $f$ is the same one in Veronesi (1999) and it was shown there it has a unique solution on the relevant domain, $\pi_{t} \in(0,1)$.

Next, we have to find the individual discounting functions, $S_{i}$. In order to do so, we use the first order conditions (10) for asset demands, $X_{t}^{*}$, and the market clearing condition $X_{t}^{*}=\omega$ to get the equalities:

$$
\begin{aligned}
r \gamma \Sigma_{p} X_{t}^{*}= & \left(\alpha_{p}+D_{t}-r P_{t}\right)-g^{\prime}\left(\pi_{t}\right) \Phi_{p} \sigma_{\pi}^{\prime} \\
r \gamma \Sigma_{p} \omega= & \left(-r-\frac{\gamma}{r^{2}} \Sigma \omega-r S\left(\pi_{t}\right)+S^{\prime}\left(\pi_{t}\right) \alpha_{\pi}+\frac{1}{2} S^{\prime \prime}\left(\pi_{t}\right) H h\left(\pi_{t}\right)^{2}\right) \\
& -\left(f^{\prime}\left(\pi_{t}\right)-r \gamma S_{m}^{\prime}\left(\pi_{t}\right)\right) \Phi_{p} \sigma_{\pi}^{\prime}
\end{aligned}
$$

If we left multiply both sides of the above expression by $e_{i}, i=1, \ldots, n$, we get individual expression 
for $S_{i}$ :

$$
\begin{aligned}
r \gamma \sigma_{i m, p}= & \left(-r-\frac{\gamma}{r^{2}} \sigma_{i m}-r S_{i}\left(\pi_{t}\right)+S_{i}^{\prime}\left(\pi_{t}\right) \alpha_{\pi}+\frac{1}{2} S_{i}^{\prime \prime}\left(\pi_{t}\right) H h\left(\pi_{t}\right)^{2}\right) \\
& -\left(f^{\prime}\left(\pi_{t}\right)-r \gamma S_{m}^{\prime}\left(\pi_{t}\right)\right) \sigma_{i p} \sigma_{\pi}^{\prime}
\end{aligned}
$$

that if we substitute for $\sigma_{i m, p}, \sigma_{i p}, \sigma_{i m}$ and $\sigma_{\pi}$ and rearrange the terms, we observe that the market discount function $S_{m}^{\prime}\left(\pi_{t}\right)$ cancels out and a differential equations for each asset $i=1, \ldots n$ is obtained:

$$
0=S_{i}^{\prime \prime}\left(\pi_{t}\right) P_{3}\left(\pi_{t}\right)+S_{i}^{\prime}\left(\pi_{t}\right) P_{2}\left(\pi_{t}\right)+S_{i}^{\prime}\left(\pi_{t}\right) r+P_{i 0}\left(\pi_{t}\right)
$$

where

$$
\begin{aligned}
P_{3}\left(\pi_{t}\right) & =-\frac{1}{2} h^{2}\left(\pi_{t}\right) H \\
P_{2}\left(\pi_{t}\right) & =\gamma h\left(\pi_{t}\right) \Delta \theta_{m}+r \gamma h\left(\pi_{t}\right)^{2} H \frac{\Delta \theta_{m}}{r(r+\mu+\lambda)}+h\left(\pi_{t}\right)^{2} H f^{\prime}\left(\pi_{t}\right)-\alpha_{\pi} \\
P_{i 0}\left(\pi_{t}\right) & =\gamma h\left(\pi_{t}\right) \frac{\Delta \theta_{i} \Delta \theta_{m}}{r(r+\mu+\lambda)}\left(2+\frac{h\left(\pi_{t}\right) H}{(r+\mu+\lambda)}\right)+f^{\prime}\left(\pi_{t}\right) \Delta \theta_{i} h\left(\pi_{t}\right)\left(\frac{h\left(\pi_{t}\right) H}{r(r+\mu+\lambda)}+\frac{1}{r}\right)
\end{aligned}
$$

This differential equation is essentially the same one in Veronesi (1999). We refer the reader to that paper for a proof that a solution exists on relevant domain, $\pi_{t} \in(0,1)$. Note that only the last term, $P_{i 0}\left(\pi_{t}\right)$, varies across assets. Furthermore, we observe that if two assets have the same $\Delta \theta_{i}$ they will share the same discounting function.

The following proposition shows that asset prices that solve the investor problem and clear the market are non-linear functions of the investor beliefs and cash-flows.

Proposition 3. [Ribeiro and Veronesi (2002)] The following asset prices solve the investor problem and clear the market:

$$
P_{i t}=p_{0 i}+\frac{D_{i t}}{r}+p_{\pi i} \pi_{t}+p_{1 i}+S_{i}\left(\pi_{t}\right)
$$


where $S_{i}$ is the solution to a differential equation given in the Appendix and

$$
\begin{aligned}
p_{0 i} & =\frac{\theta_{i B}}{r^{2}}+\frac{\left(\theta_{i G}-\theta_{i B}\right)}{r^{2}(r+\lambda+\mu)} \mu \\
p_{\pi i} & =\frac{\left(\theta_{i G}-\theta_{i B}\right)}{r(r+\lambda+\mu)} \\
p_{1 i} & =-\frac{\gamma \sigma_{i, m}}{r^{2}}
\end{aligned}
$$

for $i=1, \ldots, n$. The market portfolio is the aggregate portfolio $P_{m t}=\sum_{i=1}^{n} \omega_{i} P_{i t}$.

The $S_{i}$ function in equation (12) discounts cyclical assets and inflates countercyclical assets, generating a premium for holding risky assets. This discount (inflation) reaches a minimum (maximum) in the interior of $\pi_{t} \in(0,1)$ if the asset is cyclical (countercyclical).

From asset prices, excess returns, variances and covariances can be obtained by direct application of Ito's lemma, as the following proposition shows.

Proposition 4. Define excess return as $R_{i t}^{e} \equiv \frac{d P_{i t}}{P_{i t}}+\frac{D_{i t}}{P_{i t}} d t-r d t$. Then the following continuous process describes excess returns in terms of the model's parameters:

$$
\begin{gathered}
R_{i t}^{e}=\alpha_{i R, t} d t+\sigma_{i R, t} d v_{t} \\
\alpha_{i R}=\frac{1}{P_{i t}}\left[\frac{\gamma}{r} e_{i}^{\prime} \Sigma \omega-r S_{i}\left(\pi_{t}\right)+S_{i}^{\prime}\left(\pi_{t}\right) \alpha_{\pi}+\frac{1}{2} S_{i}^{\prime \prime}\left(\pi_{t}\right) \sigma_{\pi}^{2}\right] \\
\sigma_{i R}=\frac{1}{P_{i t}}\left[\frac{e_{i}^{\prime} \Phi}{r}+\left[S_{i}^{\prime}\left(\pi_{t}\right)+p_{\pi i}\right] \pi_{t}\left(1-\pi_{t}\right) \Delta \theta^{\prime} \Phi^{\prime-1}\right]
\end{gathered}
$$

for $i=1, \ldots, n$ assets, where $e_{i}$ is a $(n \times 1)$ vector of zeros and one at the ith row. For the market portfolio, set $i=m$ and $e_{m} \equiv \omega$. Expected excess returns are then given by $E_{t}\left[R_{i t}^{e}\right]=\alpha_{i R} d t$ and covariance between assets $i$ and $j$, where $i, j=1, \ldots, n, m$, by:

$$
\sigma_{i j, R}=\frac{1}{P_{i t} P_{j t}}\left[\left(A_{i j}+M_{i j}\left(\pi_{t}\right)\right) \pi_{t}^{2}\left(1-\pi_{t}\right)^{2}+\left(B_{i j}+N_{i j}\left(\pi_{t}\right)\right) \pi_{t}\left(1-\pi_{t}\right)+C_{i j}\right] d t
$$


where

$$
\begin{aligned}
A_{i j} & =\frac{\Delta \theta_{i} \Delta \theta_{j}}{r^{2}(r+\lambda+\mu)^{2}} \Delta \theta^{\prime} \Sigma^{-1} \Delta \theta \\
B_{i j} & =2 \frac{\Delta \theta_{i} \Delta \theta_{j}}{r^{2}(r+\lambda+\mu)} \\
C_{i j} & =\frac{1}{r^{2}} \operatorname{cov}_{t}\left(d D_{i t}, d D_{j t}\right) \\
M_{i j}\left(\pi_{t}\right) & =\Delta \theta^{\prime} \Sigma^{-1} \Delta \theta\left[S_{i}^{\prime}\left(\pi_{t}\right) S_{j}^{\prime}\left(\pi_{t}\right)+\frac{S_{i}^{\prime}\left(\pi_{t}\right) \Delta \theta_{j}+S_{j}^{\prime}\left(\pi_{t}\right) \Delta \theta_{i}}{r(\lambda+\mu+r)}\right] \\
N_{i j}\left(\pi_{t}\right) & =\frac{\left[S_{i}^{\prime}\left(\pi_{t}\right) \Delta \theta_{j}+S_{j}^{\prime}\left(\pi_{t}\right) \Delta \theta_{j}\right]}{r}
\end{aligned}
$$

The excess return variance of asset $i$ follows by setting both subscripts above to $i$.

Proof. It follows by applying Ito's lemma to the definition of excess returns.

If the investor is risk-neutral, the discounting function $S$ is zero and expected returns are proportional to the cash-flow covariance of the asset with the market portfolio, normalized by prices. If the investor is risk averse, expected returns will also depend on the conditional probability $\pi_{t}$ through the $S$ function. Increases in the discounting of prices, $-r S_{i}\left(\pi_{t}\right)$, and in their sensitivity to $\pi_{t}, S_{i}^{\prime}\left(\pi_{t}\right) \alpha_{\pi}$, imply higher expected returns. Also, higher uncertainty will command higher expected returns through the term $\frac{1}{2} S_{i}^{\prime \prime}\left(\pi_{t}\right) \sigma_{\pi}^{2}$. In addition to time-varying expected returns, the model also implies that return covariance and volatility are stochastic. 


\section{B Tables and Graphs}

\section{Table 1: NBER Business Cycles and Book-to-Market Portfolios Log-Dividend Growth}

Panel A reports the average number of months and proportion of recessions and expansions according to the NBER business cycles data. Panel A also shows the Markov-switching transition matrix parameters that is implied by NBER data, where: $\lambda \equiv \operatorname{prob}\left(S_{t+1}=\operatorname{Bad} \mid S_{t}=\operatorname{Good}\right)$ is obtained by setting the average sample duration of expansion equal to $1 / \lambda$; and $\mu \equiv \operatorname{prob}\left(S_{t+1}=\operatorname{Good} \mid S_{t}=B a d\right)$ is obtained by setting $\mu /(\mu+\lambda)$ equal to the proportion of expansionary months in the sample. Panel B reports the unconditional and conditional sample moments of the annual log-dividend growth on the 5 book-to-market portfolios. The lowest quintile portfolio is the growth portfolio and the highest quintile, the value portfolio. Log-dividend growth series are constructed from monthly returns with and without dividend payouts, as in pg. 1648 of Bansal et al. (2005). Log-dividend growth is aggregate at the annual frequency to avoid seasonal variations. Mean and standard deviations are computed for the full sample and conditional to recessionary and expansionary years, where a year is recessionary if five or more months in it were recessionary according to NBER.

Panel A: NBER Cycles (1956 - 2010)

\begin{tabular}{|c|c|c|c|c|c|c|}
\hline \multicolumn{4}{|c|}{ Sample (Months) } & \multicolumn{3}{|c|}{ Implied Transition Matrix } \\
\hline & Recessions & Expansions & & $\mathbf{t} \mid \mathbf{t}+\mathbf{1}$ & Good State & Bad State \\
\hline Average & 11.22 & 62.22 & & Good State & 0.984 & 0.016 \\
\hline Proportion & 0.17 & 0.83 & & Bad State & 0.080 & 0.920 \\
\hline \multicolumn{7}{|c|}{ Panel B: Log-Dividend Growth Sample Moments (1956 - 2010) } \\
\hline & \multicolumn{3}{|c|}{ Mean } & \multicolumn{3}{|c|}{ Standard Deviation } \\
\hline & Full Sample & Recession & Expansion & Full Sample & Recession & Expansion \\
\hline Growth & 0.0487 & 0.0579 & 0.0464 & 0.0888 & 0.0742 & 0.0927 \\
\hline Qnt 2 & 0.0479 & 0.0324 & 0.0506 & 0.1040 & 0.1089 & 0.1039 \\
\hline Qnt 3 & 0.0558 & -0.0026 & 0.0704 & 0.1021 & 0.1053 & 0.0970 \\
\hline Qnt 4 & 0.0519 & -0.0192 & 0.0697 & 0.1196 & 0.1985 & 0.0848 \\
\hline Value & 0.0610 & -0.1305 & 0.1089 & 0.1769 & 0.2438 & 0.1173 \\
\hline
\end{tabular}




\section{Table 2: Calibration Parameters, Model and Sample Moments}

Panel A reports the parameters that calibrated the cash-flow processes, defined by the equation $(1) . \theta_{G, i}\left(\theta_{B, i}\right)$ is the cash-flow drift of asset $i$ in the good (bad) state. $\sigma_{D, i}$ is the standard deviation of asset $i$ 's cash-flow. The correlation parameters, $\rho_{i j}$, are set equal to $0.25,0.15,0.10$ and 0.05 for $|i-j|$ equal to $1,2,3$ and 4 , respectively. Both standard deviation vector and correlation matrix are used to determine the diffusion term $\Phi$, which is the same across the two states. Panel B reports the main numbers that result from the calibration and from the model's pricing equations. $\Delta \theta_{i} \equiv \theta_{G, i}-\theta_{B, i}$ is a measure of the asset's sensitivity to shifts. $\bar{\theta}_{i}=\pi_{s} \theta_{G, i}+\left(1-\pi_{s}\right) \theta_{B, i}$ is the unconditional or long-run drift, where $\pi_{s} \equiv \mu /(\mu+\lambda)=0.83$. $E\left[r_{i}^{e x}\right]$ is the unconditional excess return or, equivalently, the conditional excess return when $\pi_{t}=\pi_{s} . \sigma_{r, i}$ is the unconditional standard deviation of asset's $i$ excess return or, equivalently, the conditional standard deviation when $\pi_{t}=\pi_{s}$. Panel C reports the sample moments of the empirical counterparts in Panel B. The sample moments from the five book-to-market portfolios monthly were computed from monthly data from 1956 to 2010, and then annualized.

Panel A: Calibrated Parameters

\begin{tabular}{|c|c|c|c|c|c|}
\hline & A1 & A2 & A3 & A4 & A5 \\
\hline$\theta_{G, i}$ & 0.040 & 0.059 & 0.066 & 0.074 & 0.100 \\
\hline$\theta_{B, i}$ & 0.050 & 0.000 & -0.020 & -0.040 & -0.130 \\
\hline$\sigma_{D, i}$ & 0.160 & 0.135 & 0.130 & 0.130 & 0.090 \\
\hline \multicolumn{6}{|c|}{ Panel B: Model's Implied Parameters } \\
\hline & A1 & A2 & A3 & A4 & A5 \\
\hline$\Delta \theta_{i}$ & -0.010 & 0.059 & 0.086 & 0.114 & 0.230 \\
\hline $\bar{\theta}_{i}$ & 0.042 & 0.049 & 0.052 & 0.055 & 0.062 \\
\hline$E\left[r_{i}^{e x}\right]$ & $3.49 \%$ & $4.85 \%$ & $5.51 \%$ & $5.95 \%$ & $8.22 \%$ \\
\hline$\sigma_{r, i}$ & 0.151 & 0.135 & 0.141 & 0.152 & 0.213 \\
\hline \multicolumn{6}{|c|}{ Panel C: Book-to-Market Sample Parameters } \\
\hline & Growth & Qnt 2 & Qnt 3 & Qnt 4 & Value \\
\hline $\bar{\theta}_{i}$ & 0.049 & 0.048 & 0.056 & 0.052 & 0.061 \\
\hline$\sigma_{D, i}$ & 0.089 & 0.104 & 0.102 & 0.120 & 0.177 \\
\hline$E\left[r_{i}^{e x}\right]$ & $3.50 \%$ & $4.81 \%$ & $5.96 \%$ & $6.53 \%$ & $8.03 \%$ \\
\hline$\sigma_{r, i}$ & 0.190 & 0.166 & 0.165 & 0.181 & 0.198 \\
\hline
\end{tabular}




\section{Table 3: Descriptive Statistics of Beliefs and Uncertainty Proxies}

This Table shows the descriptive statistics of the proxies for investor beliefs and uncertainty. The beliefs proxy, $\hat{\pi}_{t}$, are the probabilities that the economy is in the good state implied by a two-state Markov-switching model fitted to the excess return on the market portfolio. The uncertainty proxy $\hat{\pi}_{t}\left(1-\hat{\pi}_{t}\right)$ is directly computed from investor

beliefs, $\hat{\pi}_{t}$. The other proxy for uncertainty is $V I X$, the Chicago Board Options Exchange (CBOE) volatility index, which is a measure of the implied volatility of S\&P 500 index options.

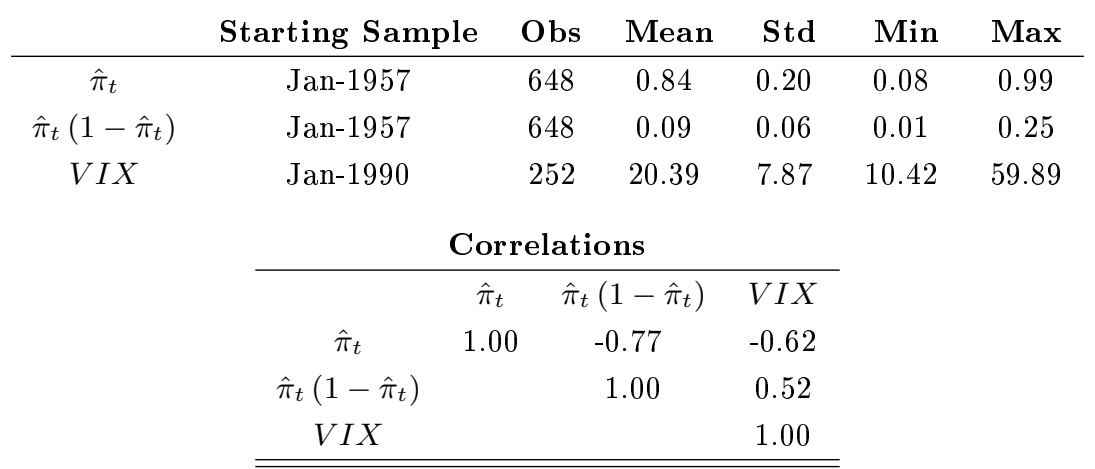




\section{Table 4: 5 Book-to-Market Portfolios Conditional Betas}

This Table shows the GMM estimated parameters from the monthly excess returns on the five book-to-market portfolios from 1956 to 2010 that results from the moment restrictions:

$$
E\left\{\left[r_{i, t}-\alpha_{i}-\beta_{m i, t} r_{m, t}\right] \otimes Z_{t}\right\}=\mathbf{0}
$$

for $i=1, \ldots, 5$. Two different specifications for market betas are considered: $\beta_{m i, t}=a_{1, i}+a_{2, i} \hat{\pi}_{t}+a_{3, i} \hat{\pi}_{t}^{2}$, denoted model (M1), and $\beta_{m i, t}=a_{4, i}+a_{5, i} U C_{t}$, denoted model (M2). $\hat{\pi}_{t}$, is a proxy for investor beliefs implied by the probabilities of a two-state Markov-switching model fitted to the excess return on the market portfolio. In model (M2), $U C_{t}$ can be one of two investor uncertainty proxies: $U C_{t}=\hat{\pi}_{t}\left(1-\hat{\pi}_{t}\right)$, directly obtained from $\hat{\pi}_{t}$, or $U C_{t}=V I X_{t}$, the Chicago Board Options Exchange (CBOE) volatility index, a measure of the implied volatility of S\&P 500 index options. The instruments used to estimate the parameters in (M1) are $Z_{t}=\left[\begin{array}{lllll}1 & r_{m, t} & \hat{\pi}_{t} r_{m, t} & \hat{\pi}_{t}^{2} r_{m, t}\end{array}\right]^{\prime}$ and the instruments in (M2) are $Z_{t}=\left[\begin{array}{lll}1 & r_{m, t} & U C_{t} r_{m, t}\end{array}\right]^{\prime}$. Both models are exactly identified. The long-run covariance matrix of the moments is estimated with the Newey-West kernel and the optimal bandwidth.

\begin{tabular}{|c|c|c|c|c|c|c|c|}
\hline & & & Growth & Qnt 2 & Qnt 3 & Qnt 4 & Value \\
\hline M1 & $\alpha_{i}$ & param & 0.0031 & 0.0045 & 0.0057 & 0.0063 & 0.0072 \\
\hline \multirow[t]{7}{*}{ Mar-56 to Dec-10 } & & t-stat & 4.47 & 6.54 & 7.24 & 5.87 & 5.95 \\
\hline & $a_{1, i}$ & param & 1.11 & 1.00 & 1.03 & 0.90 & 0.94 \\
\hline & & t-stat & 12.92 & 10.76 & 14.43 & 5.74 & 5.55 \\
\hline & $a_{2, i}$ & param & -0.26 & -0.51 & -0.63 & 0.15 & 0.41 \\
\hline & & t-stat & -0.99 & -1.29 & -1.60 & 0.22 & 0.55 \\
\hline & $a_{3, i}$ & param & 0.20 & 0.55 & 0.54 & -0.22 & -0.45 \\
\hline & & t-stat & 0.97 & 1.74 & 1.49 & -0.39 & -0.70 \\
\hline \multirow{6}{*}{$\begin{array}{c}\text { M2 } \\
U C_{t}=\hat{\pi}_{t}\left(1-\hat{\pi}_{t}\right) \\
\text { Mar-56 to Dec-10 }\end{array}$} & $\alpha_{i}$ & param & 0.0031 & 0.0045 & 0.0057 & 0.0063 & 0.0072 \\
\hline & & t-stat & 4.44 & 6.64 & 7.15 & 5.85 & 5.94 \\
\hline & $a_{4, i}$ & param & 1.05 & 1.05 & 0.93 & 0.82 & 0.90 \\
\hline & & t-stat & 41.60 & 39.69 & 23.72 & 18.69 & 15.45 \\
\hline & $a_{5, i}$ & param & -0.05 & -0.69 & -0.29 & 0.39 & 0.52 \\
\hline & & t-stat & -0.21 & -3.58 & -0.86 & 0.90 & 1.00 \\
\hline \multirow{6}{*}{$\begin{array}{c}\text { M2 } \\
U C_{t}=\hat{\pi}_{t}\left(1-\hat{\pi}_{t}\right) \\
\text { Jan-90 to Dec-10 }\end{array}$} & $\alpha_{i}$ & param & 0.0028 & 0.0045 & 0.0042 & 0.0046 & 0.0053 \\
\hline & & t-stat & 2.39 & 3.74 & 2.62 & 2.22 & 2.52 \\
\hline & $a_{4, i}$ & param & 1.03 & 0.98 & 0.90 & 0.81 & 0.82 \\
\hline & & t-stat & 22.98 & 17.99 & 11.18 & 9.11 & 8.23 \\
\hline & $a_{5, i}$ & param & -0.14 & -0.57 & -0.17 & 0.30 & 0.88 \\
\hline & & t-stat & -0.39 & -1.67 & -0.27 & 0.39 & 1.03 \\
\hline \multirow{6}{*}{$\begin{array}{c}\text { M2 } \\
U C_{t}=V I X_{t} \\
\text { Jan-90 to Dec-10 }\end{array}$} & $\alpha_{i}$ & param & 0.0021 & 0.0045 & 0.0049 & 0.0058 & 0.0060 \\
\hline & & t-stat & 1.81 & 3.18 & 2.68 & 2.59 & 2.51 \\
\hline & $b_{4, i}$ & param & 1.13 & 0.93 & 0.77 & 0.62 & 0.77 \\
\hline & & t-stat & 24.97 & 11.32 & 7.35 & 4.67 & 5.36 \\
\hline & $b_{5, i}$ & param & -0.42 & -0.09 & 0.38 & 0.77 & 0.59 \\
\hline & & t-stat & -3.29 & -0.42 & 1.46 & 2.47 & 1.61 \\
\hline
\end{tabular}




\section{Table 5: Book-to-Market Betas (Beliefs)}

This Table shows the GMM estimated parameters from the monthly excess returns on 10 book-to-market from 1956 to 2010 that results from the moment restrictions:

$$
E\left\{\left[r_{i, t}-\alpha_{i}-\left(a_{1, i}+a_{2, i} \hat{\pi}_{t}+a_{3, i} \hat{\pi}_{t}^{2}\right) r_{m, t}\right] \otimes Z_{t}\right\}=\mathbf{0}
$$

for $i=1, \ldots, 40$ where $\beta_{i, t}=a_{1, i}+a_{2, i} \hat{\pi}_{t}+a_{3, i} \hat{\pi}_{t}^{2} \cdot \hat{\pi}_{t}$, is a proxy for investor beliefs implied by the probabilities of a two-state Markov-switching model fitted to the excess return on the market portfolio. The instruments used to estimate the parameters in (M1) are $Z_{t}=\left[\begin{array}{lllll}1 & r_{m, t} & \hat{\pi}_{t} r_{m, t} & \hat{\pi}_{t}^{2} r_{m, t}\end{array}\right]^{\prime}$ and so the model is exactly identified. The long-run covariance matrix of the moments is estimated with the Newey-West kernel and the optimal bandwidth.

\begin{tabular}{ccccccccc} 
& \multicolumn{9}{c}{ params } \\
Portfolios & $\alpha_{i}$ & $a_{1, i}$ & $a_{2, i}$ & $a_{3, i}$ & $\alpha_{i}$ & $a_{1, i}$ & $a_{2, i}$ & $a_{3, i}$ \\
\hline Low BEME & -0.018 & 1.000 & 0.158 & -0.085 & -1.711 & 8.66 & 0.40 & -0.26 \\
$\mathbf{2}$ & -0.002 & 1.021 & -0.324 & 0.345 & -0.279 & 13.54 & -0.85 & 1.04 \\
$\mathbf{3}$ & 0.004 & 0.798 & 0.154 & 0.092 & 0.551 & 5.39 & 0.31 & 0.24 \\
$\mathbf{4}$ & 0.005 & 1.037 & -0.550 & 0.553 & 0.543 & 8.49 & -1.00 & 1.17 \\
$\mathbf{5}$ & 0.016 & 0.902 & -0.346 & 0.393 & 1.585 & 8.81 & -0.70 & 0.89 \\
$\mathbf{6}$ & 0.017 & 0.961 & -0.305 & 0.281 & 1.905 & 6.50 & -0.56 & 0.64 \\
$\mathbf{7}$ & 0.020 & 0.594 & 1.155 & -0.948 & 1.673 & 3.42 & 1.45 & -1.43 \\
$\mathbf{8}$ & 0.031 & 0.931 & -0.024 & -0.039 & 2.366 & 3.36 & -0.02 & -0.05 \\
$\mathbf{9}$ & 0.036 & 0.790 & 0.701 & -0.624 & 2.943 & 4.35 & 0.91 & -0.97 \\
High BEME & 0.039 & 0.966 & 0.722 & -0.715 & 2.222 & 3.15 & 0.67 & -0.83 \\
\hline \hline
\end{tabular}




\section{Table 6: Book-to-Market Betas (Uncertainty)}

This Table shows the GMM estimated parameters from the monthly excess returns on 10 book-to-market from 1956 to 2010 that results from the moment restrictions:

$$
E\left\{\left[r_{i, t}-\alpha_{i}-\left(a_{4, i}+a_{5, i} U C_{t}\right) r_{m, t}\right] \otimes Z_{t}\right\}=\mathbf{0}
$$

for $i=1, \ldots, 40$ where $\beta_{i, t}=a_{4, i}+a_{5, i} U C_{t} . U C_{t}$ can be one of two investor uncertainty proxies: i $) U C_{t}=\hat{\pi}_{t}\left(1-\hat{\pi}_{t}\right)$, directly obtained from $\hat{\pi}_{t}$, the proxy for investor beliefs implied by the probabilities of a two-state Markov-switching model fitted to the excess return on the market portfolio; and ii) $U C_{t}=V I X_{t}$, the Chicago Board Options Exchange (CBOE) volatility index, a measure of the implied volatility of S\&P 500 index options. The instruments are $Z_{t}=\left[\begin{array}{llll}1 & r_{m, t} & U C_{t} r_{m, t}\end{array}\right]^{\prime}$ and so the model is exactly identified. The long-run covariance matrix of the moments is estimated with the Newey-West kernel and the optimal bandwidth.

\begin{tabular}{ccccccc} 
& \multicolumn{3}{c}{ params } & \multicolumn{3}{c}{ t-stat } \\
Port. & $\alpha_{i}$ & $a_{4, i}$ & $a_{5, i}$ & $\alpha_{i}$ & $a_{4, i}$ & $a_{5, i}$ \\
\hline Low BEME & -0.014 & 1.17 & -0.39 & -0.82 & 16.04 & -1.81 \\
$\mathbf{2}$ & 0.002 & 0.96 & -0.03 & 0.12 & 13.36 & -0.22 \\
$\mathbf{3}$ & 0.005 & 1.02 & -0.35 & 0.37 & 8.52 & -0.76 \\
$\mathbf{4}$ & 0.040 & 0.68 & 0.89 & 1.87 & 6.70 & 3.79 \\
$\mathbf{5}$ & 0.027 & 0.73 & 0.49 & 1.16 & 5.17 & 1.08 \\
$\mathbf{6}$ & 0.024 & 0.68 & 0.79 & 1.25 & 7.34 & 3.53 \\
$\mathbf{7}$ & 0.024 & 0.77 & 0.19 & 0.85 & 5.66 & 0.70 \\
$\mathbf{8}$ & 0.046 & 0.44 & 1.42 & 1.79 & 3.12 & 3.03 \\
$\mathbf{9}$ & 0.034 & 0.75 & 0.52 & 1.35 & 5.75 & 1.84 \\
High BEME & 0.052 & 0.66 & 1.32 & 1.44 & 3.70 & 1.97 \\
\hline \hline
\end{tabular}


Table 7: Asymmetric Betas $-\beta_{+}(c)$ and $\beta_{-}(c)$

This Table reports the p-values of the statistic $J_{\beta}=T\left(\beta_{+}-\beta_{-}\right)^{\prime} \hat{\Psi}^{-1}\left(\beta_{+}-\beta_{-}\right)$, where $\beta_{+}(c)=\frac{\operatorname{cov}\left(\tilde{r}_{i, t}, \tilde{r}_{m, t} \mid \tilde{r}_{m, t}>c\right)}{\operatorname{var}\left(\tilde{r}_{m, t} \mid \tilde{r}_{m, t}>c\right)}$ and $\beta_{-}(c)=\frac{\operatorname{cov}\left(\tilde{r}_{i, t}, \tilde{r}_{m, t} \mid \tilde{r}_{m, t}<-c\right)}{\operatorname{var}\left(\tilde{r}_{m, t} \mid \tilde{r}_{m, t}<-c\right)}$, with $\tilde{r}$ denoting standardized returns and $c$ thresholds. The null hypothesis is $H_{0}:$ $\beta_{+}(c)=\beta_{-}(c)$, for all $c \geq 0$ versus $H_{a}: \beta_{+}(c) \neq \beta_{-}(c)$, for some $c \geq 0 . \overline{\beta_{+}-\beta_{-}}$refers to the average of the vector $\beta_{+}-\beta_{-}=\left[\beta_{+}\left(c_{1}\right)-\beta_{-}\left(c_{1}\right), \ldots, \beta_{+}\left(c_{n}\right)-\beta_{-}\left(c_{n}\right)\right]^{\prime}$.

\begin{tabular}{ccc} 
& \multicolumn{2}{c}{$c=[0,0.1, \ldots, 1.5]$} \\
Portfolios & p-value & $\overline{\beta_{+}-\beta_{-}}$ \\
\hline Low. BEME & 0.004 & 0.037 \\
$\mathbf{2}$ & 0.451 & 0.086 \\
$\mathbf{3}$ & 0.080 & 0.082 \\
$\mathbf{4}$ & 0.852 & 0.054 \\
$\mathbf{5}$ & 0.564 & 0.030 \\
$\mathbf{6}$ & 0.261 & -0.050 \\
$\mathbf{7}$ & 0.990 & 0.113 \\
$\mathbf{8}$ & 0.480 & -0.045 \\
$\mathbf{9}$ & 0.102 & -0.049 \\
High. BEME & 0.049 & -0.092 \\
\hline \hline
\end{tabular}



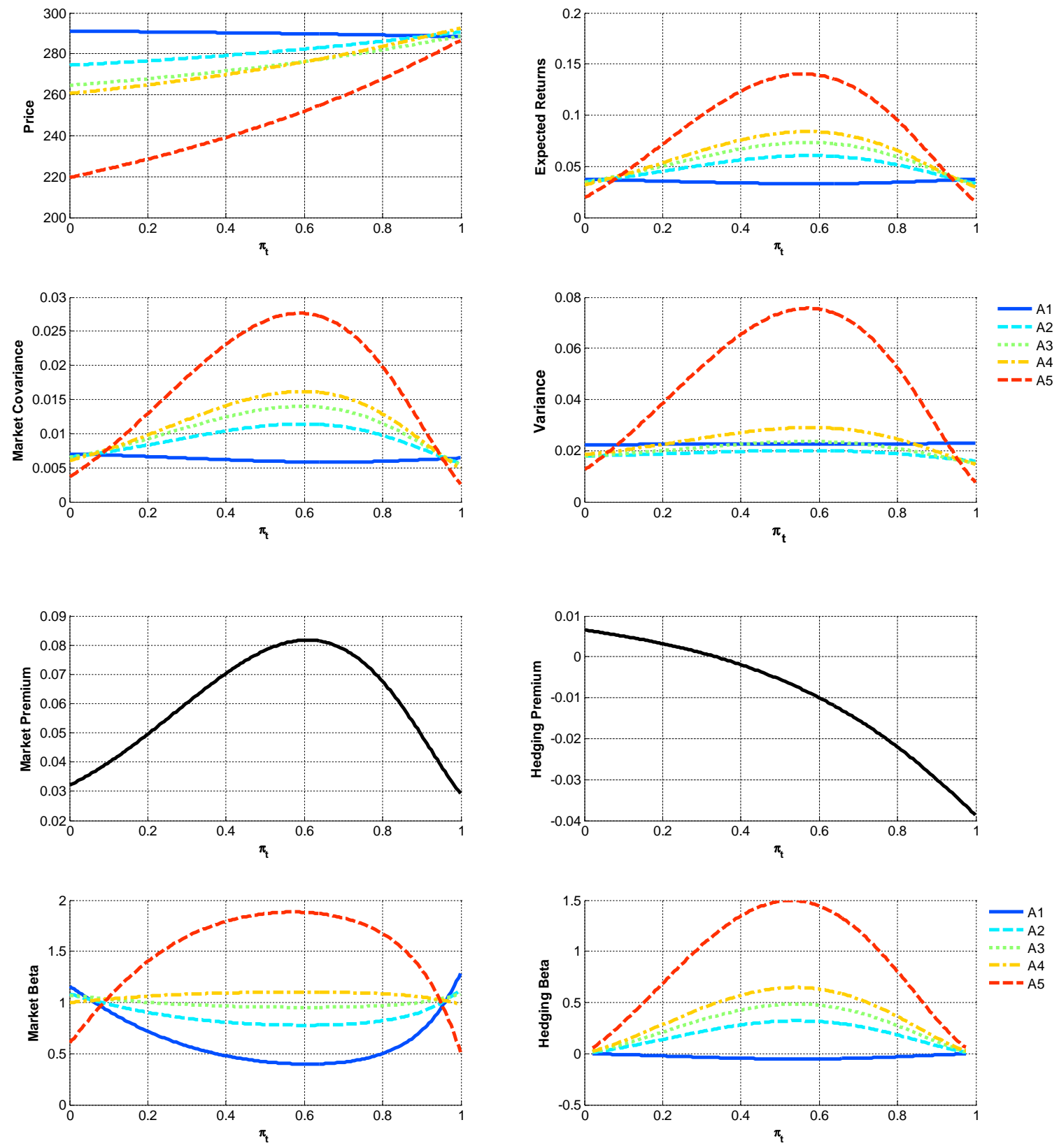

Figure 1: Theoretical Expressions Conditional on $\pi_{t}$ 


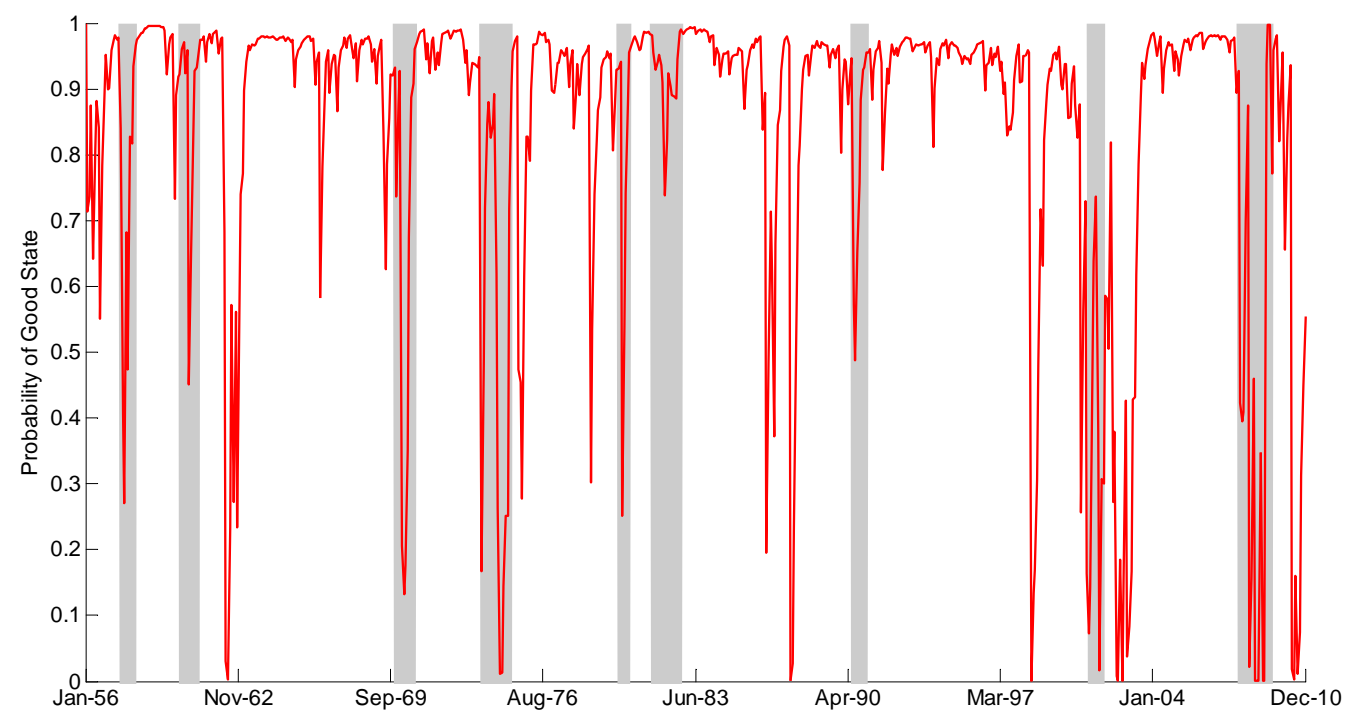

Figure 2: Markov-Switching Implied Beliefs $\hat{\pi}_{t}$ 


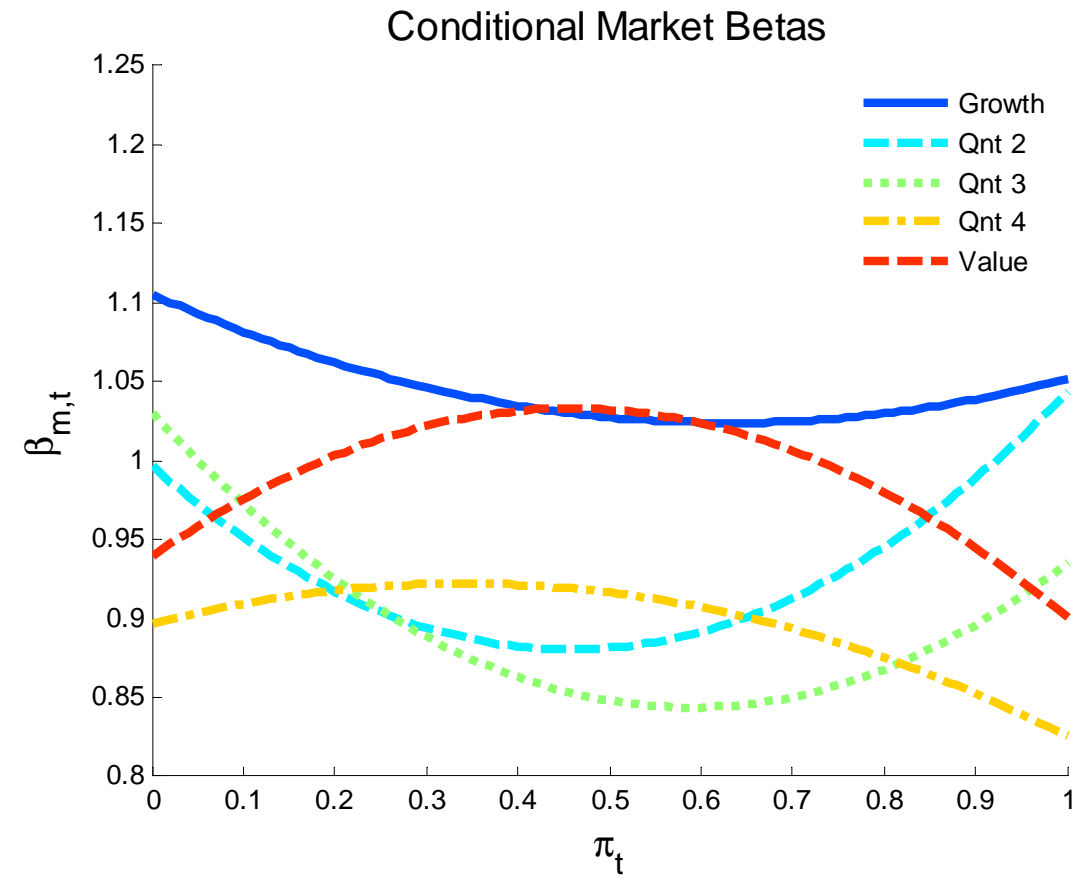

Figure 3: Estimates of Model (M1) of Conditional Betas (1956-2010) 

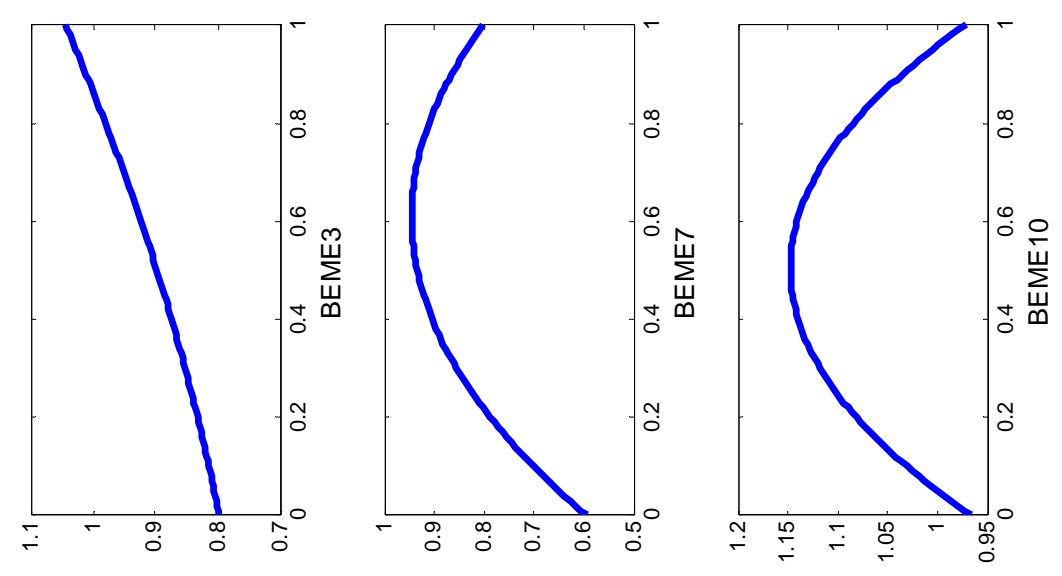

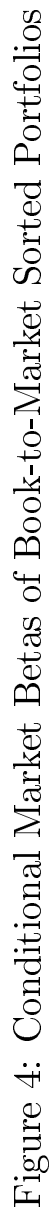
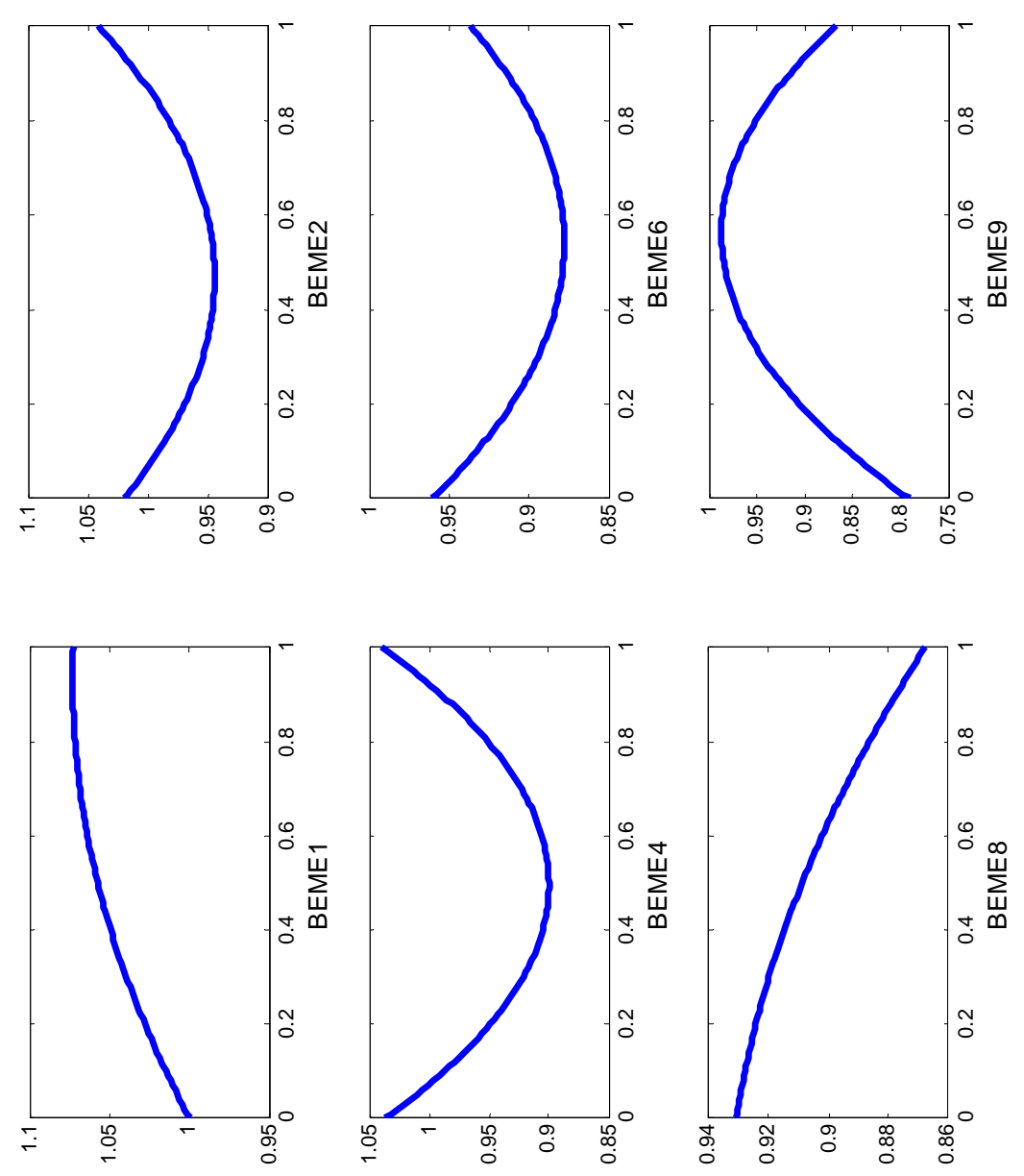


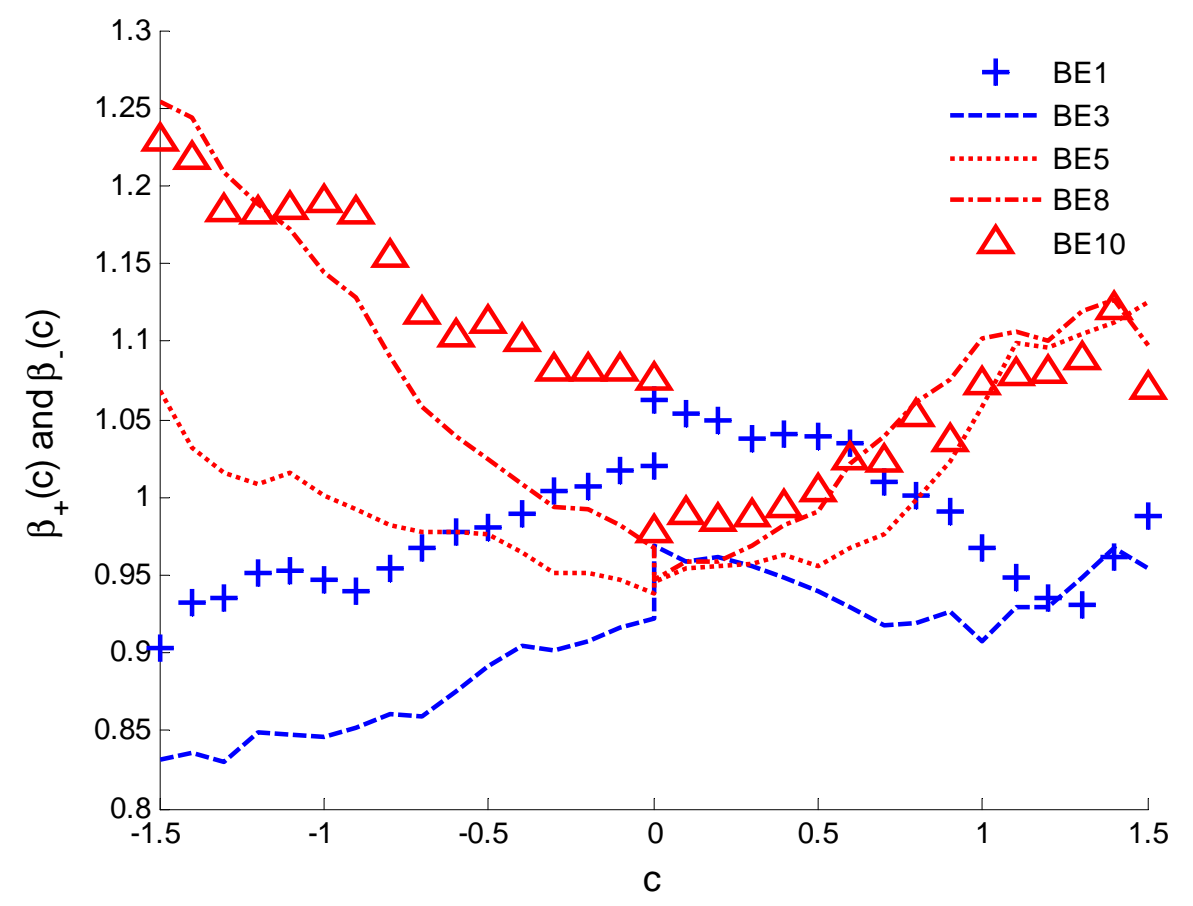

Figure 5: Market Betas Conditional to News 